\title{
Regulation and expression of sexual differentiation factors in embryonic and extragonadal tissues of Atlantic salmon
}

\author{
Kristian R von Schalburg ${ }^{1}$, Motoshige Yasuike', Ryosuke Yazawa², Johan G de Boer ${ }^{1}$, Linda Reid', Stacy So', \\ Adrienne Robb ${ }^{1}$, Eric B Rondeau', Ruth B Phillips ${ }^{3}$, William S Davidson ${ }^{4}$, Ben F Koop ${ }^{1 *}$
}

\begin{abstract}
Background: The products of cyp19, dax, foxl2, mis, sf1 and sox9 have each been associated with sex-determining processes among vertebrates. We provide evidence for expression of these regulators very early in salmonid development and in tissues outside of the hypothalamic-pituitary-adrenal/gonadal (HPAG) axis. Although the function of these factors in sexual differentiation have been defined, their roles in early development before sexual fate decisions and in tissues beyond the brain or gonad are essentially unknown.

Results: Bacterial artificial chromosomes containing salmon dax 1 and dax2, fox $12 b$ and mis were isolated and the regulatory regions that control their expression were characterized. Transposon integrations are implicated in the shaping of the dax and fox 12 loci. Splice variants for cyp19b1 and mis in both embryonic and adult tissues were detected and characterized. We found that cyp19b1 transcripts are generated that contain 5'-untranslated regions of different lengths due to cryptic splicing of the $3^{\prime}$-end of intron 1 . We also demonstrate that salmon mis transcripts can encode prodomain products that present different C-termini and terminate before translation of the MIS hormone. Regulatory differences in the expression of two distinct aromatases cyp19a and cyp19b1 are exerted, despite transcription of their transactivators (ie; dax1, foxl2, sf1) occurring much earlier during embryonic development.

Conclusions: We report the embryonic and extragonadal expression of dax, fox 12 , mis and other differentiation factors that indicate that they have functions that are more general and not restricted to steroidogenesis and gonadogenesis. Spliced cyp1961 and mis transcripts are generated that may provide regulatory controls for tissueor development-specific activities. Selection of cyp1961 transcripts may be regulated by DAX-1, FOXL2 and SF-1 complexes that bind motifs in intron 1, or by signals within exon 2 that recruit splicing factors, or both. The potential translation of proteins bearing only the N-terminal MIS prodomain may modulate the functions of other TGF $\beta$ family members in different tissues. The expression patterns of dax 1 early in salmon embryogenesis implicate its role as a lineage determination factor. Other roles for these factors during embryogenesis and outside the HPAG axis are discussed.
\end{abstract}

\section{Background}

Sex determination and early gonadal development depends upon specific embryonic gene programs that activate differentiation of the bipotential primodium. These processes hinge upon the expression of both sexlinked and autosomal genes that promote or antagonize

\footnotetext{
* Correspondence: bkoop@uvic.ca

'Department of Biology, Centre for Biomedical Research, University of

Victoria, Victoria, British Columbia, V8W 3N5, Canada

Full list of author information is available at the end of the article
}

male or female cell fate pathways. The products of some genes are essential for female (WNT-4 (Wingless-related MMTV integration site-4) and follistatin) [1] and male (SRY (Sex-determining region of the Y chromosome) and FGF-9 (fibroblast growth factor-9)) [2] sex-determination in mammals. In mammals, as well as teleosts, DAX-1 (Dosage-sensitive sex reversal, adrenal hypoplasia congenital, critical region on the $\mathrm{X}$-chromosome, gene-1), FOXL2 (forkhead box L2), cytochrome P450 aromatase, MIS (Mullerian inhibiting substance), SF-1 (steroidogenic

\section{Biomed Central}


factor-1), SOX-9 (SRY-related, high-mobility group (HMG) box (SRY box)-9), WT-1 (Wilm's tumour-1) [3-6] and many other gene products contribute in directing sex-determined fates, as well as to subsequent gonad development and function [7-9 and refs. therein].

SF-1 is central to the activity of many of these genes as well as a large component of steroidogenic genes. Both SF-1 and DAX-1 are orphan receptors for which no ligand has yet been unequivocally identified, but which do possess ligand-binding domains [10]. SF-1 and DAX-1 interact cooperatively or antagonistically to influence various target gene activities [10]. DAX-1 modulates transcription of genes such as aromatase [11] and MIS [12] through direct interactions with SF1 and the recruitment of other factors. Functional interactions of SF-1 with WT-1 or DAX-1 promotes or inhibits the expression of MIS [13]. The products of dax 1 , foxl2 and $s f 1$ each play critical roles in the transcriptional regulation of aromatase (cyp19) genes [6,11,14-17].

Elucidation of the factors that promote or repress the transcription of these differentiation factors will also help to characterize the regulatory programs they initiate. Conservation of transcription factor binding motifs in the promoters of mammalian and teleost genes point to shared regulatory regimes. The expression patterns of the genes described here may be deciphered in part by examination of their promoter regions. Antagonism between DAX-1 and FOXL2 or SF-1 and SOX factors may be common themes for activation or repression among many of these differentiation factors [11,18-23].

Although our understanding of the action of various sex determination and differentiation factors in early gonad development is well-established, our knowledge of other roles that these regulators may play before formation of sexual tissues is limited. Sex-specific regulation of various steroidogenic and differentiation regulators in trout have been demonstrated by molecular studies to occur about one month before observable morphological differences [5]. Histologically discernable features of gonad differentiation in salmonids become manifest approximately five weeks after hatching $[5,14]$.

In the Atlantic salmon (Salmo salar), we have detected the expression of $d a x 1 / 2$, foxl $2 a / b$ and mis (and $s f 1$ and sox 9 factors) more than three weeks before even the hatching stage. In this paper we show that the genes we examined were expressed several months before morphologically discernable differentiation of the gonad. This is the first time, other than for dax1, that this has been demonstrated for the genes we selected. We also demonstrate broad expression of these regulators in various extragonadal adult tissues. Therefore genes previously considered to be involved in gonadogenesis and steroidogenesis are apparently more general in their transcriptional programming, at least in salmon.

Furthermore, we have isolated, sequenced and assembled BACs containing these genes and analyzed their proximal promoters. Our expression studies also reveal unique splicing activities that occur among some of these regulators. Taken together, we suggest that the roles of $d a x 1 / 2$, foxl $2 a / b$, mis and $s f 1$ are not confined to differentiation and development of gonadal (and brain) cell lineages and examine the potential influence of the novel splicing and transcriptional regulatory mechanisms of these factors within and outside the HPAG axis.

\section{Results}

\section{Stages that present challenges during development}

To characterize the stages of development of the Atlantic salmon and identify potentially problematic stages, we assayed mortality rates during embryonic and larval development. The day of fertilization was Day (D) 0, and hatching and yolk sac absorption occurred between D38 to D40 and D68 to D70, respectively. Images of selected stages taken during the course of early development are presented in Figure 1. We counted the mortalities each collection day during the development study. We found that there were at least four stages which can present potential developmental challenges (see Additional file 1). One stage comes at D13.5, the point at which we noted eye formation was initiated. Next, from D38 to D50 is a period when hatching had begun. Most larvae hatched between D38 and D40, but there also were a large number for which hatching was delayed. The large peak at D49 (see Additional file 1) marks 184 mortalities due to late, incomplete or unsuccessful hatching. Many larvae in this group failed to complete hatching or had survival problems once hatched. The two small peaks that follow this period represent morphological abnormalities that arose during alevin development (ie; curved backs).

\section{Early expression of sex differentiation factors}

It became increasingly clear from preliminary studies that the expression of known sex differentiation regulators were expressed much earlier in salmonid development than we had expected. To determine when expression of these sex differentiation factors was initiated, we prepared RNA from embryos two days post-fertilization (D2) and succeeding time points. Our RT-PCR results show that the mRNA for many of these genes is present very early in development (Figure 2), at least one month ahead of previously characterized expression of regulators linked to differentiation of the salmonid gonad $[5,14]$. It was necessary to reamplify the early amplification products of 


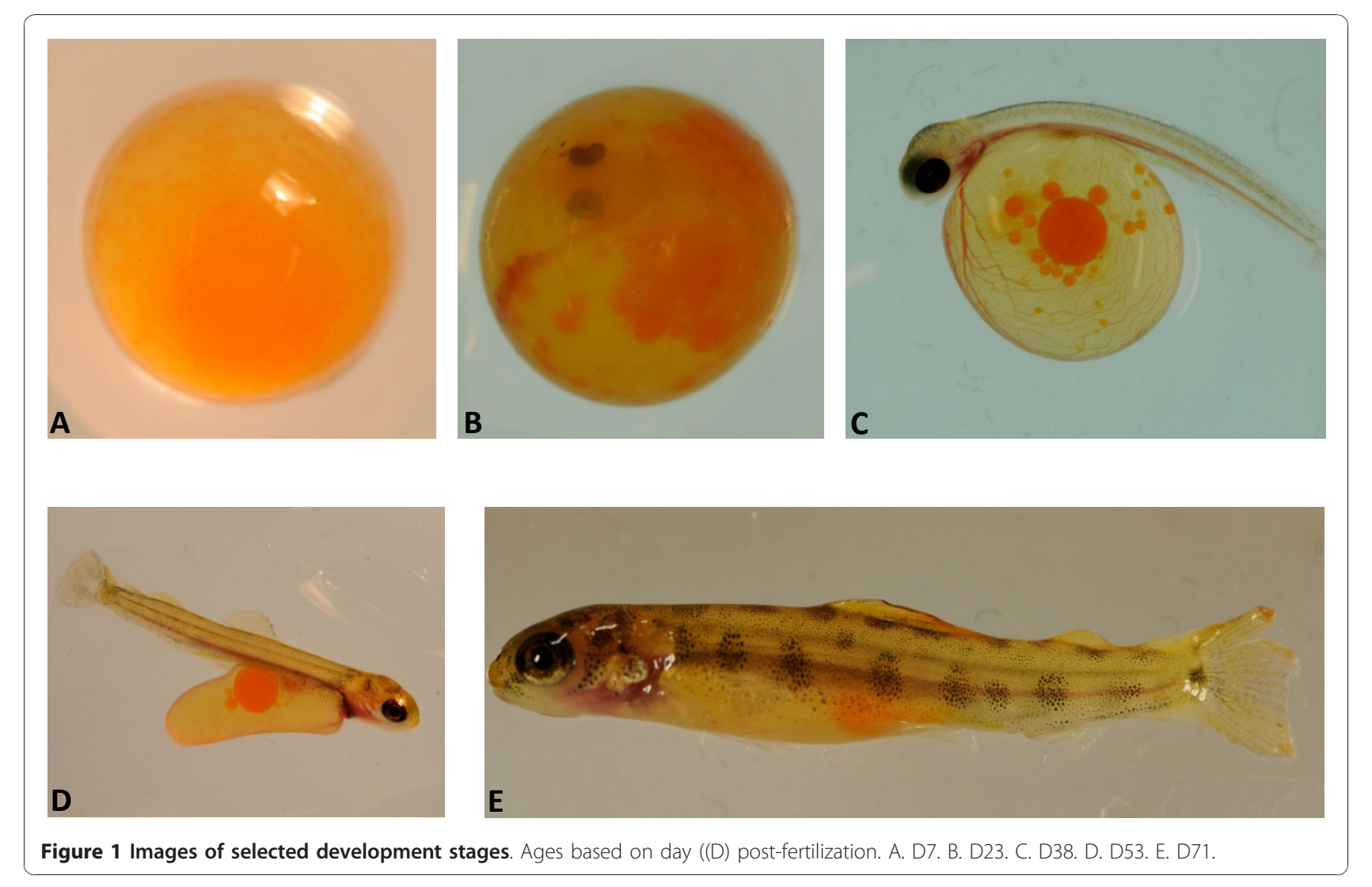

dax2, foxl2a, foxl2b, mis and $s f 1$ for presentation in Figure 2. We do not know if these transcripts are maternally contributed or if they are the result of zygotic transcription. To the best of our knowledge, for the genes we detected at these early stages, there presently is only evidence for the expression of dax 1 in embryonic cells in mammals [24].

Also of interest are the gene expression results for larvae and alevin between D38 to 77. It is known that dax 1, foxl2 and $s f 1$ expression correlates with transcription of cyp $19 a$ in many species $[6,11,14,16,17,25,26]$. We therefore were interested in examining the expression of these regulators in relationship to cyp $19 a$ transcription. Most if not all of the genes known to be involved in aromatase transactivation were expressed during this period (Figure 3). cyp19b1 was expressed weakly as early as D21 (Figure 2), but weak expression of cyp19a was not detected until at least D47 (Figure 3). The earliest "strong" detection of the expression of cyp $19 a$ was D59, nearly two months after the earliest expression of its regulators (Figure 3). Thus, although the genes (and presumably their protein products) important to cyp19a regulation were present, it was not until three weeks later (D59) that cyp19a transcription was strongly detected (Figure 3). This is similar to findings that were made for ovary-specific cyp19a expression in trout [5]. This time point may be considered a mark of the earliest molecular expression of steroidogenic and differentiation factors before morphologically distinguishable features of sex differentiation [5].

\section{Expression of sex differentiation factors in various adult tissues}

Most of the information available on the genes we examined is from investigations done on the brain or gonadal tissue (eg; endocrine organs). We therefore explored the expression of each gene in twelve tissues extracted and prepared from three different male and female adult fish. Analysis of the RT-PCR results indicates that most of these genes were expressed quite broadly (see Additional file 2). We were most surprised to find the expression of $s f 1$, mis and both sox 9 genes across all tissues examined, particularly in the male. It was also interesting to compare the expression patterns between paralogs where it was possible to distinguish potential regulatory differences between foxl2a and foxl2b, and cyp $19 a$ and cyp $19 b 1$ transcripts (see Additional file 2). We also detected the expression of multiple products for cyp $19 b 1$ and mis and these amplicons were isolated, cloned and sequenced. 


\section{$2510121416182021 \mathrm{M}$}

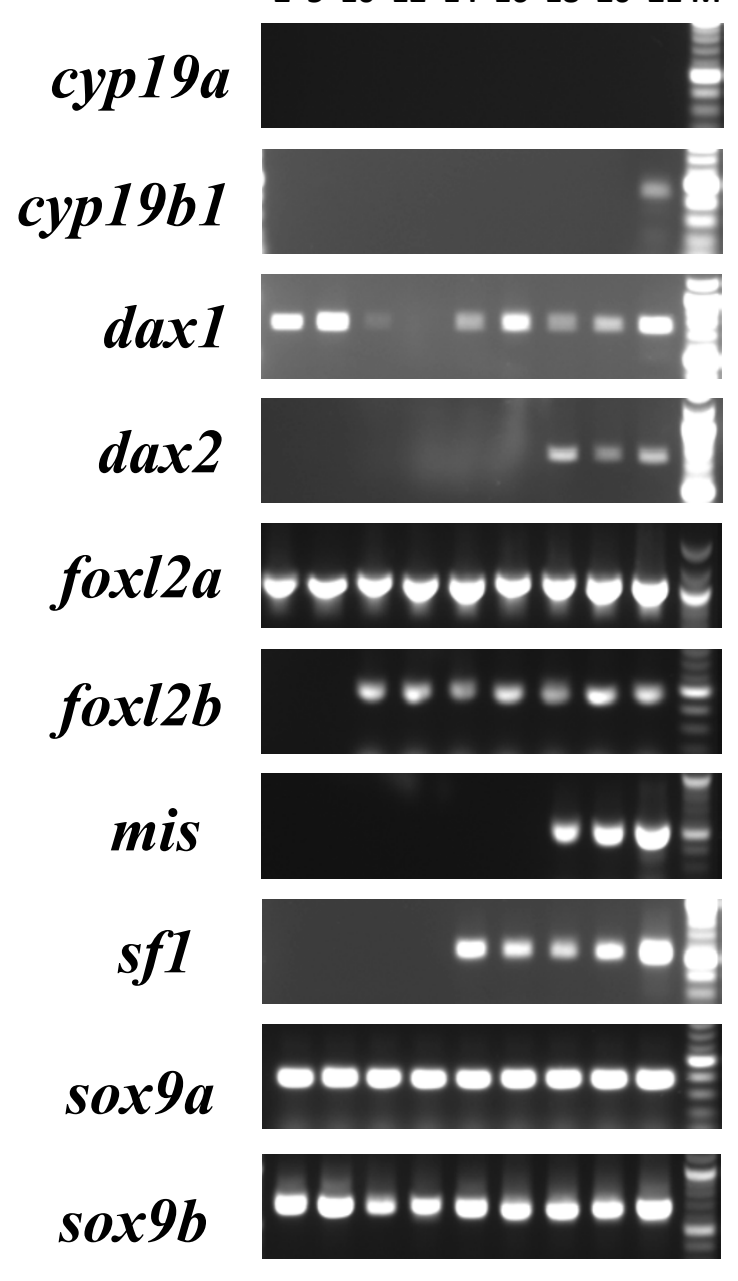

Figure 2 Reverse-transcriptase PCR validation of gene-specific CDNA expression during embryonic stages of development. Development stage indicated by day (Days 2 through 21) postfertilization. For determining the lengths of each amplicon, the strongest marker bands indicate fragment lengths of $500 \mathrm{bp}$ (cyp19b1, foxl2b, mis, sf1, sox9a and sox9b) or 1000 bp (dax1, dax2 and fox $(2 a)$.

\section{Alternative splicing of mis transcripts}

MIS is a member of the TGF superfamily of proteins that share features that are conserved across many species from fish to mammals [27], each containing an $\mathrm{N}$-terminal prodomain and a $\mathrm{C}$-terminal domain that presents MIS. Proteolysis of the prodomain from the C-terminal domain at specific protease recognition motifs is required to release the hormone activity of MIS [27]. We isolated three transcripts of different sizes for mis. The primer set used was designed against sequence that spans a region of DNA that encodes potential enzymatic cleavage recognition residues and that is upstream from the bioactive hormone region of the molecule (nts 27979 to 28608 [GenBank:HM159473]) (Figure 4A).
We found expression of a complete sequence (629 bp), and two alternatively-spliced transcripts of 436 and $396 \mathrm{bp}$ in length (see Additional file 3). Similar alternatively-spliced variants of mis have also been characterized in the European sea bass [27]. The mis (629 bp) and mis (436 bp) transcripts terminate 22 and 47 codons downstream from their putative protease RLRR recognition motifs, respectively (Figure 4B). Translation of these transcripts thereby does not generate the C-terminal mature hormone portion of salmon MIS. Only mis (396 bp) is in-frame to encode the bioactive hormone portion of the gene (Figure $4 \mathrm{C}$ ).

The features of the different mis transcripts may be important for different regulatory capacities, depending on the tissue in which they are expressed. For example, mis (629 bp) is expressed at relatively high levels in the muscle, skin, gill, spleen, brain and heart; mis (436 bp) is most "strongly" expressed in the gonad (as well as the kidney and eye), and mis (396 bp) is expressed at a relatively low level in most of the male tissues we examined (see Additional file 2). Other potential alternativelyspliced amplicons of mis are observed in several of the female tissues.

In the early development stages, expression of mis was first observed on D18 and we did detect the expression of multiple mis amplicons by D27 (data not shown). We attempted to clone and sequence each of these PCR products, but were successful in obtaining information for only the larger $629 \mathrm{bp}$ transcript.

\section{Alternative splicing of cyp19b1 transcripts}

During the process of preparing clones for sequencing to confirm their identities, we isolated and sequenced cyp19b1 transcripts of three different sizes from D38 larvae. Previous work demonstrated that at least five different cyp $19 b 1$ transcripts that bear differences in the lengths of their 5'-UTRs are generated in the brain and gonads of rainbow trout $[23,28]$. We now show similar results for the transcription of cyp19b1 transcripts with 5'-UTRs of a variety of lengths in Atlantic salmon.

The salmon transcript 1 utilizes the more conventional intron 1/exon 2 splice sites and is devoid of intron 1 (Figure 5). Transcript 2 has been previously identified in the trout brain and gonads $[23,28]$ and includes a portion of the 3'-end of intron 1 of the salmon cyp $19 b 1$ gene (Figure 5 and 6). Transcript 3 contains an extra 69 nts of intron 1, in addition to the most 3 '-end of the intron that is included in the 5 '-end of transcript 2. This is the first time that a cyp19b1 transcript using this more upstream splice site has been reported for a salmonid. Each of these distinct mRNAs use splice sites that follow the canonical pre-mRNA GT-AG rule for intron splicing [29]. It is interesting that the cryptic 3 '-splice site utilized in transcript 2 is 


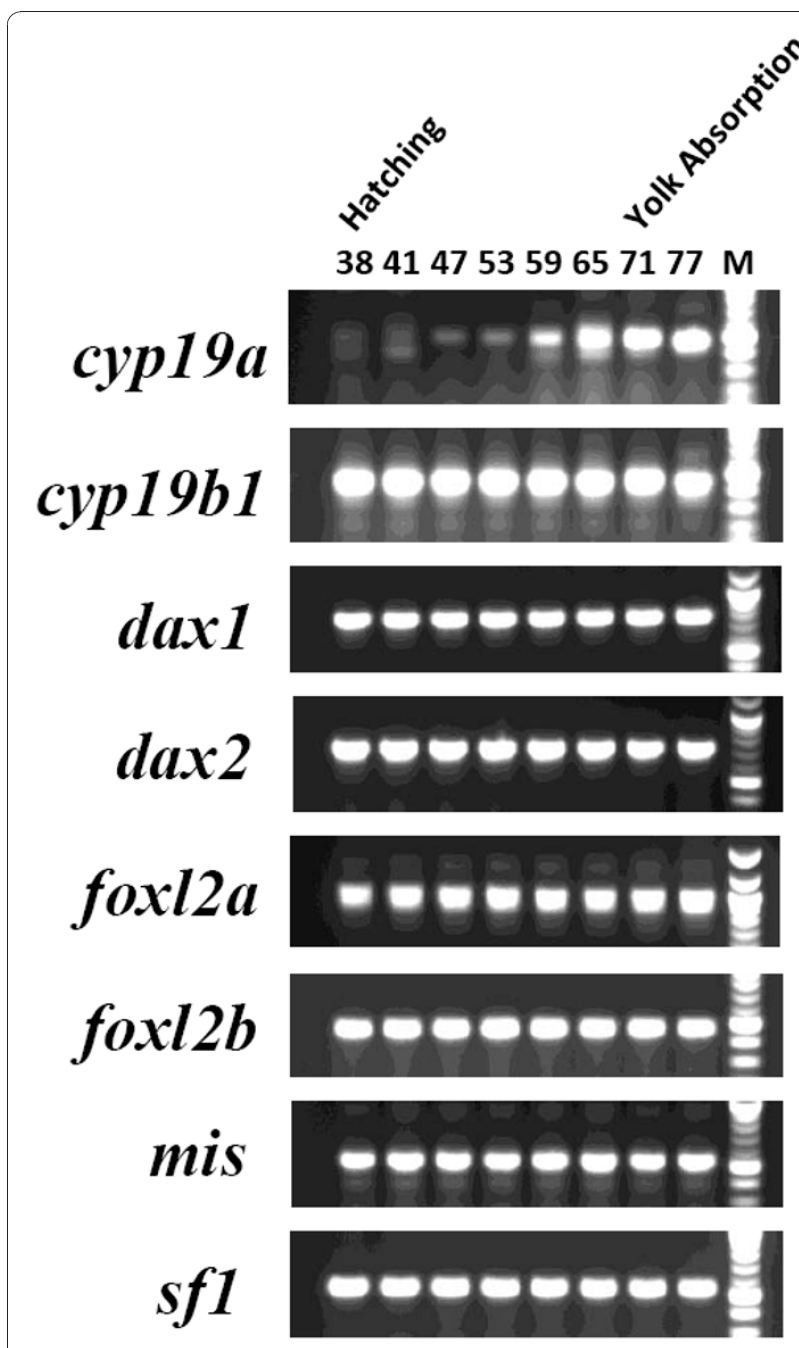

Figure 3 Reverse-transcriptase PCR validation of gene-specific cDNA expression in larval and alevin stages of development. Development stage indicated by day (Days 38 through 77) postfertilization. For determining the lengths of each amplicon, the strongest marker bands indicate fragment lengths of $500 \mathrm{bp}$ (cyp19a, cyp19b1, fox12b, mis and sf1) or 1000 bp (dax1, dax2 and fox/2a).

bypassed by the spliceosome in favour of the more upstream acceptor AG site in transcript 3. Of eight cyp19b1 clones isolated from amplifications of D38 cDNA, six were transcript 2 representatives. We presume that other examples of these partial intron 1containing cyp19b1 transcripts exist. However, several of the larger (>521 bp), weaker cyp19b1 PCR products detected in the adult tissues were isolated, cloned and sequenced and determined to be non-specific amplifications (see Additional file 2).

Generally, strong 3'-splice sites in vertebrate intronic regions contain a pyrimidine-rich tract and a terminal AG $[29,30]$. These sequences are important for spliceosome recognition for precise intron removal [30]. Examining the
$30 \mathrm{nts}$ preceeding each of the three 3'-splice sites in intron 1 of cyp $19 b 1$ revealed that the conventional intron 1 /exon 2 junction, the cryptic 3 '-splice site and the most upstream splice site had 33\% (1), 53\% (2) and 63\% (3) CT content, respectively (Figure 5). Interestingly, the splice site with the least pyrimidine content is that of the more conventional intron 1 /exon 2 junction. It is therefore possible that the formation of this junction is the least favoured of the three splice sites presented here.

A comparison of the rainbow trout [GenBank: AJ716203] and Atlantic salmon cyp19b1 intron 1 shows strong conservation in the 5'-and 3'-ends (data not shown). The central region of the two introns contain indels and are less conserved. Interestingly, only one intronic repeat sequence (IRS) segment, previously reported as four contiguous blocks of 46 nts in the trout [23], was present in the salmon cyp19b1 intron 1 (Figure 6). The loss of the other three IRSs in the Atlantic salmon comprises almost half of the difference in the sizes between the introns (trout: $1264 \mathrm{bp}$; salmon: $964 \mathrm{bp}$ ).

The novelty of the cryptic 3'-splicing in the cyp19b1 intron 1 [23, 28 and refs therein] suggests this region is a target for regulators that bind signal elements within it to dictate distinct splicing events. Interestingly, a cluster of perfect and imperfect core recognition motifs for FOXL2 (5'-(G/A)(T/C)(C/A)AA(C/T)A-3' $[16,25,26])$ are located in the salmon cyp19b1 intron 1 (Figure 6). The IRS contains at least one potential half-site (AGGACCT) that could potentially bind estrogen receptor or retinoic acid receptor-retinoid $\mathrm{X}$ receptor heteromers. The IRS is also flanked by two everted SF-1 motifs that present only one mismatch to the consensus sequence YCAAGGYCR, where $\mathrm{Y}=\mathrm{T} / \mathrm{C}$ and $\mathrm{R}=\mathrm{G} / \mathrm{A}$ [31 and refs therein].

Recent viral and mammalian work has demonstrated that exonic splicing signals exist that can enhance (ESEs) or suppress (ESSs) spliceosome recognition for intron splice sites [30]. Although this class of RNA processing signal is ill-defined in fish, we previously identified several putative exonic splicing enhancers and suppressors in exon 2 of trout cyp19b1 [23]. These ESEs and ESSs are almost identical in the Atlantic salmon cyp $19 b 1$ exon 2 (data not shown), indicating that this exon contains significantly positioned splicing motifs that could also potentially direct the lengths of the 5'-end of cyp19b1 mRNAs.

\section{Conservation of nucleocytoplasmic transport signals in SOX9}

The N-terminal high mobility group (HMG), DNAbinding domain of the characterized salmonid SOX-9 proteins are highly conserved, even in comparison to the mouse and human SOX-9 proteins (Figure 7). Signals important for the import and export of SOX-9 between the cytoplasm and the nucleus have been identified $[32,33]$. In particular, the bipartite and basic cluster 


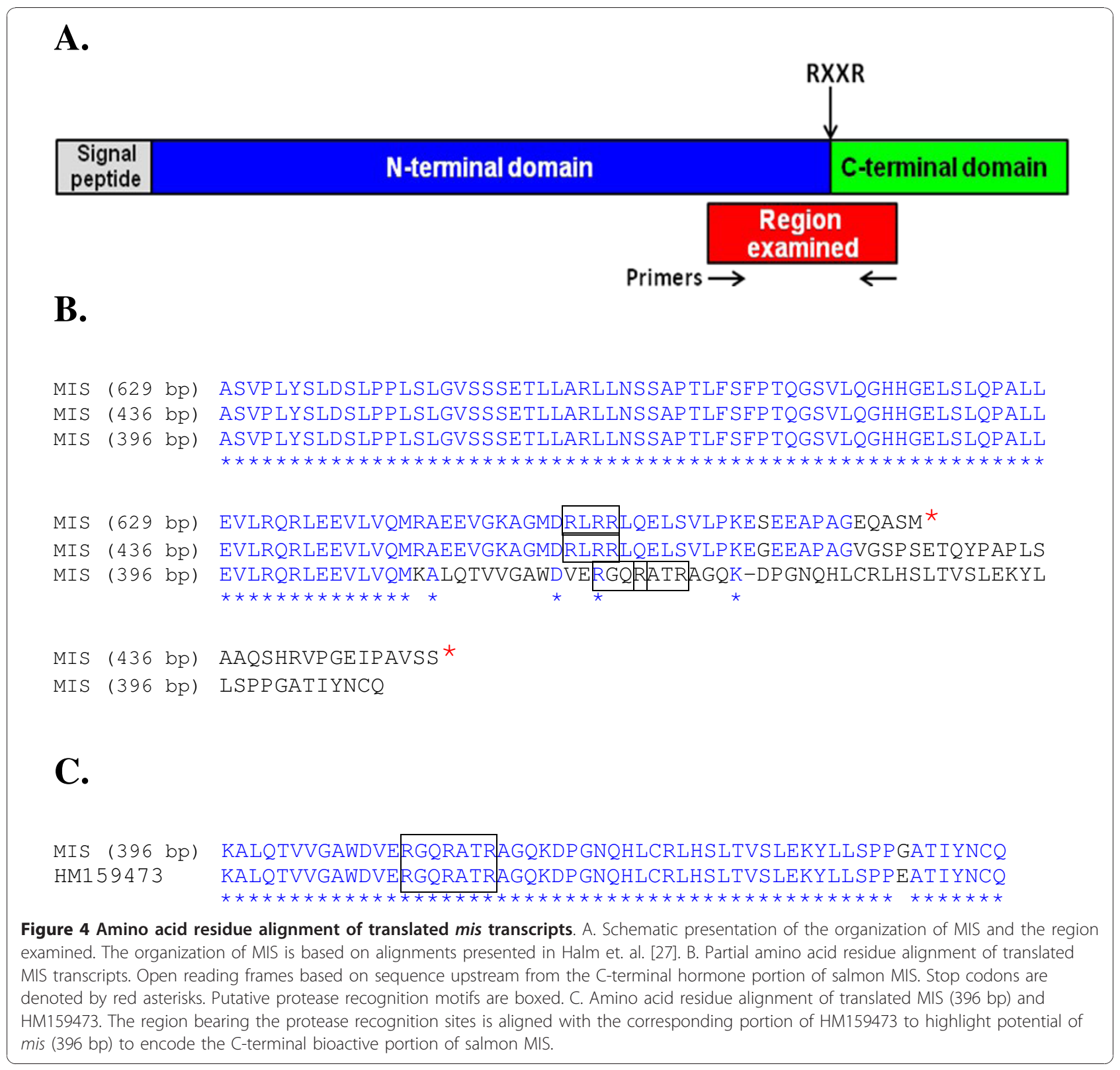

nuclear localization signals (NLS-1 and -2) [32], as well as the leucine-rich nuclear export signal (NES) [33] are $100 \%$ identical across the species examined (Figure 7 ). The largest divergence between the mammalian and salmonid SOX-9 proteins occurs in the C-terminal nonHMG, protein-interface and transactivation domain (data not shown).

\section{BAC organization and regulatory regions}

In order to understand more fully the regulatory regions and chromosomal context of specific factors thought to be important in sexual differentiation processes in salmon, we isolated several BACs containing $\operatorname{dax} 1$ and dax 2 , foxl $2 b$ and mis. Once the BACs had been isolated and assembled, we examined approximately $3.5 \mathrm{~kb}$ of sequence in the proximal promoter regions and identified a number of different transcription factor response elements for each gene of interest (GOI). As well, the chromosomal environment in which each GOI resides is presented in Figure 8.

The mammalian dax 1 promoter contains binding sites for OCT3/4, SOX-2, SF-1 and other regulatory factors [20]. We show both of the salmonid dax promoters contain binding elements for SF-1 and SOX-2 factors, but that only the dax 1 proximal promoter contains OCT3/4 motifs (see Additional files 4 and 5 ). The possibility exists 
transcript 1

transcript 2

transcript 3

transcript 1

transcript 2

transcript 3

transcript 1

transcript 2

transcript 3

transcript 1

transcript 2

transcript 3

transcript 1

transcript 2

transcript 3

transcript 1

transcript 2

transcript 3

transcript 1

transcript 2

transcript 3
ACAGCAGTGGCTACACAGGAGACGGACACAAACTGTAGCCAGGCTAGAGG

ACAGCAGTGGCTACACAGGAGACGGACACAAACTGTAGCCAGGCTAGAGG

ACAGCAGTGGCTACACAGGAGACGGACACAAACTGTAGCCAGGCTAGAGG

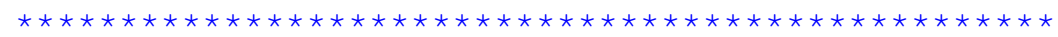

CAGACTACTCTGGGGCAGTCCAGGATGAGAGCG-----------------

CAGACTACTCTGGGGCAGTCCAGGATGAGAGCG---------------CAGACTACTCTGGGGCAGTCCAGGATGAGAGCGATAAGCGACACCTACTT

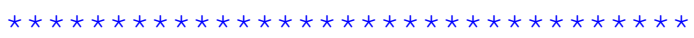

CGGTGAGGTGCAAACCAGTGGGGCATGATTTACTTTTAAAATATTTAACC

--GTAGTCTCCTTGAAGTAAGTCAGAAGACCTTTTCCCTGGGGAGATAAT

AGGTAGTCTCCTTGAAGTAAGTCAGAAGACCTTTTCCCTGGGGAGATAAT

------------------------------------CTGTCATCATAAC

ACTTGGAAGGAGAATAATTAAAGCAGAGTGCTCCAGCTGTCATCATAAC ACTTGGAAGGAGAATAATAATAGCAGAGTGCTCCAGCTGTCATCATAAC

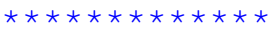

$\begin{array}{llllllll}M & \text { A } & \text { T } & \text { S } & \text { I } & \text { V } & \text { D } & \text { D }\end{array}$

ACAGCAGCCTCCAGACCTCCTCACTGTAATGGCTACCAGTATAGTGGACG ACAGCAGCCTCCAGACCTCCTCACTGTAATGGCTACCAGTATAGTGGACG ACAGCAGCCTCCAGACCTCCTCACTGTAATGGCTACCAGTATAGTGGACG

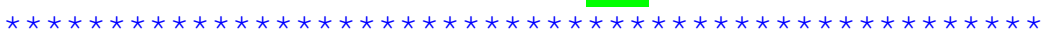

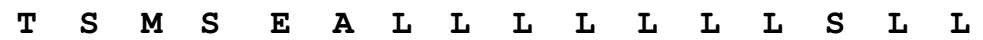

ACACTAGCATGTCTGAAGCCCTGCTGCTGCTGCTGCTGCTCTCTCTCCTG ACACTAGCATGTCTGAAGCCCTGCTGCTGCTGCTGCTGCTCTCTCTCCTG ACACTAGCATGTCTGAAGCCCTGCTGCTGCTGCTGCTGCTCTCTCTCCTG

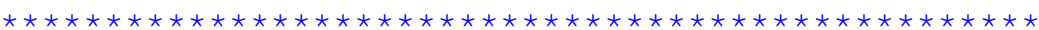

Figure 5 Sequences of alternative $5^{\prime}$-ends found in three different salmon cyp19b1. transcripts. Transcripts 2 and 3 contain spliced sections of the $3^{\prime}$-end of intron 1 in comparison to transcript 1. The position of the initiator ATG start codon in exon 2 is highlighted.

that these promoters could also be regulated by estrogen receptor since both have potential palindromic EREs. Other clear differences are discernable in the regulation of these two genes, most notably in the large regions of CT- and GA-rich regions in $\operatorname{dax} 2$ that are not present in dax1 (see Additional files 4 and 5). The GA-rich region is contiguous with a block of DNA that contains at least four perfect repeats, each 40 nts in length.

We could not identify any canonical SOX binding elements in the proximal mis promoter. However, we did detect two potential half-AREs and the presence of two SOX footprints [34] (see Additional file 6). Several OCT3/4, PPARE and WT-1 response elements were also identified. As well, typical GC boxes are located in the mis promoter (5'-GGGGCGGGGC-3') that could bind SP-1 and Kruppel-like factors [35].
We found a tetrapartite GCAT sequence in the foxl $2 b$ promoter that might bind SMAD factors. SMADs can act through GCNT, GCCG and GCAT sequence motifs [36]. Interestingly, the fox $l 2 b$ promoter does not contain a strong consensus SF-1 binding motif. However, it is possible that a weaker site at -802 to -795 (5'-TCAGGCCA-3') could interact with SF-1 (see Additional file 7). We also provide evidence that FOXL2 may regulate its own expression through several binding sites present in its promoter. Numerous potential binding sites for ERE, RXR/RAR and WT-1 are also located in the foxl2 promoter.

We also isolated a BAC containing the fox $12 a$ pseudogene. The pseudogenic foxl $2 a$ mRNA, if transcribed, would share similarity with the characterized trout orthologs beginning in regions approximately 240 and 260 nts downstream from the start codon of the 


\section{ACAGCAGTGGCTACACAGGAGACGGACACAAACTGTAGCCAGGCTAGAGGCAGACTACTCTGGGGCAGTC}

CAGGATGAGAGCGgtGAGTATTATCCTTTTCCTACATAATGACAATTCTATAAATAGGGGGAACTTTTTG

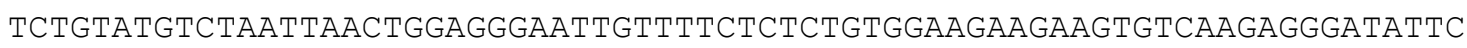
TTGAAAAGAGGCCTATAACAGAATAAGAAATATATTGAAATTTGTACAATTETAAACAFAAAAAATAAT TAAAATCTGTAтTATACAATGTTACAGCAAAAAAAACTTCTAGAGGGGATGATGACGAGAACAAAGCTGA

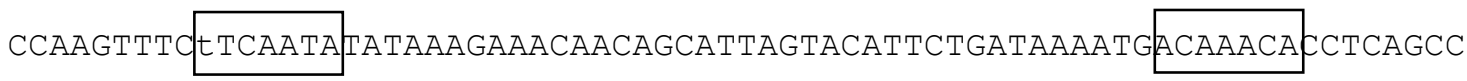

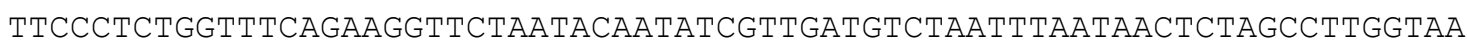
GACAtCTGGAACTGTTCATGCAATAGTACAACTGGTCAACtFGAAAAGCTTTCCGTGGGTGTGTTATGGT GACCTTGTTACCGTGTTCACATGTTGTACCAACCCCATAGGGCAAGGACAGGAGAAATATTAAAAAGGGG ATGAAAAGAGAGCAAGGGTTGTCACGGAGTTTAATGCTTCCCTATTTTGTTTTGACAATTTGAATCCCCC TGTCTACGTdCCAAATgGCACCCTATTCCCTATTTAGTGCACTACTTTTAACCAGGACCTATAGGGCTCT

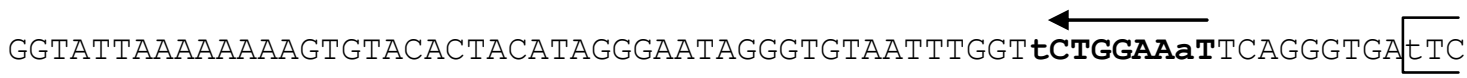

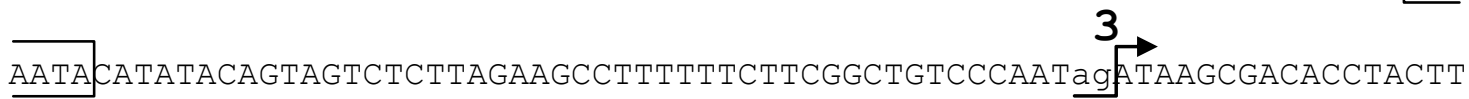
CGGTGAGGTECAAACCA ATGGGACATGATTTACTTTTAAAATATTTAACCag GTAGTCTCCTTGAAGTAA

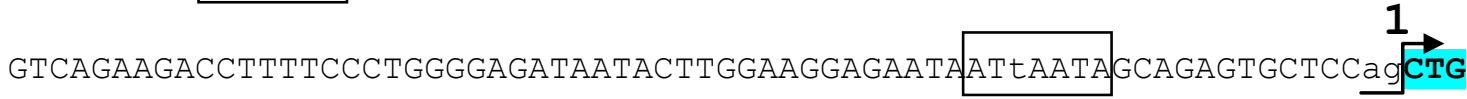
TCATCATAACACAGCAGCCTCCAGACСTCCTCACTGTAATGGCTACCAGTATAGTGGACGACACTAGCAT GTCTGAAGCCСTGCTGCTGCTGCTGCTGCTCTCTCTCCTGCTCATCACGACCTGGTGCCTCACTAATACC

TCACACATACCAGgtAAGACCAATGATGTATGAATGATGTGTGAATGTGTCTACGGGGAAAACACAGCCA стCTCTCTCCGTCTAACAACTATCACTACCGTGTAATATGAAATGTCATAATGTCTTTTTGTTGATCAT

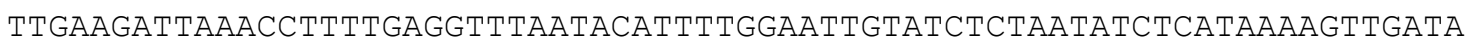
GCCAATAGTTAACTAGAAAGACATTGGCTATTCATCTAATATAACGGTTATTACTGTAAGAAGGTGGCAA

Figure 6 Sequence of Atlantic salmon cyp19b1 exon 1, intron 1 and exon 2. Boxed sequences represent putative binding elements of FOXL2. Arrows indicate the direction of potential regulatory motifs for SF-1 shown in bold. Numbers 1, 2 and 3 show the positions of each of the three AG acceptor 3'-splice sites within intron 1 that can be selected by the spliceosome to generate different 5'-UTRs in cyp19b1. An intronic repeat sequence (IRS) segment is shown in italics and enclosed by asterisks. Exons 1 and 2 are highlighted in bold and the ATG translation start site is shown in exon 2.

ortholog [GenBank:AY507927] and the diverged paralog [Genbank:AY507926] (see Additional file 8). We could find no inframe ATG initiation codons for the pseudogene in sequence upstream from these regions. Furthermore, multiple stop codons in the pseudogenic reading frame would disable any possible generation of a full-length protein. A comparison of the salmon pseudogene with the trout FOXL2 open reading frame shows a region of only short identity with the forkhead domain with the $\mathrm{N}$-and $\mathrm{C}$-terminal ends diverging completely (Figure 9). However, we did isolate an amplicon of 1010 nts that represents the salmon foxl $2 a$ based on 
Trout Sox9b [GenBank:AB006448] Salmon SOX9b [GenBank:BT059262] Trout sox9a [GenBank:AF209872] Mouse Sox9 [GenBank:NP_035578] Human SoX9 [GenBank:NP_000337]

Trout Sox9b [GenBank:AB006448] Salmon SOX9b [GenBank:BT059262] Trout sox9a [GenBank:AF209872] Mouse Sox9 [GenBank:NP_035578] Human sox9 [GenBank:NP_000337]

Trout sox9b [GenBank:AB006448] Salmon Sox9b [GenBank:BT059262] Trout Sox9a [GenBank: AF209872] Mouse Sox9 [GenBank:NP_035578] Human sox9 [GenBank:NP_000337]

Trout Sox9b [GenBank:AB006448] Salmon SOX9b [GenBank:BT059262] Trout Sox9a [GenBank: AF209872] Mouse Sox9 [GenBank:NP 035578] Human Sox9 [GenBank:NP_000337]
MNLLDPFLKMTDEQEKCFSDAPSPSMSEDSVGSPCPSGSGSDTENTRPSD MNLLDPFLKMTDEQEKCFSDAPS PSMSDDSVGSPCPSGSGSDTENTRPSD MNLLDPFLKMTDEQDKCLSDAPSPSMSEDSVGSPCPSGSGSDTENTRPSE MNLLDPFMKMTDEQEKGLSGAPS PTMSEDSAGSPCPSGSGSDTENTRPQE MNLLDP EMKMTDEQEKGLSGAPSPTMSEDSAGSPCPSGSGSDTENTRPQE

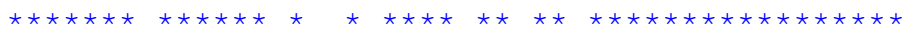

100

NHLLLGPDGVLGEFKKADQDKFPVCIRDAVSQVLKGYDWTLVPMPVRLNG NHLLLGPDGVLGEFKKADQDKFPVCIRDAVSQVLKGYDWTLVPMPVRVNG NGLLMGPDGPLVEFKKDDDDKFPVCIRDAVSQVLKGYDWTLVPMPVRMNG NTFP---KGEPDLKKESEEDKFPVCIREAVSQVLKGYDWTLVPMPVRVNG NTFP---KGEPDLKKESEEDKFPVCIREAVSQVLKGYDWTLVPMPVRVNG

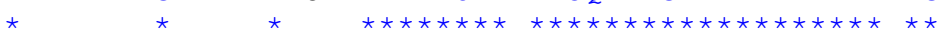

NLS-1

NES 150 SSKNKPHY KRPMNAFMVWAQAARRKLADQYPHLHNA ELSKTLGKLWRLLN SSKNKPHYKRPMNAFMVWAQAARRKLADQYPHLHNA ELSKTLGKLWRLLN SSKNKPHYKRPMNAFMVWAQAARRKLADQY PHLHNA ELSKTLGKLWRLLN SSKNKP HY KRPMNAFMVWAQAARRKLADQY PHLHNA ELSKTLGKLWRLLN SSKNKPHYKRPMNAFMVWAQAARRKLADQY PHLHNA ELSKTLGKLWRLLN

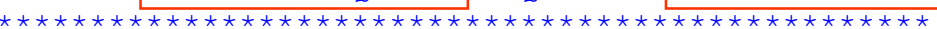

NLS-2

200 EGEKRPFVEEAERLRVQHKKDHPDYKYQPRRRKS VKNGQSEPEDGEQ-TH EGEKRPFVEEAERLRVQHKKDHPDYKYQPRRRKS VKNGQSEPEDGEQ-TH EGEKRP FVEEAERLRVQHKKDHPDYKYQPRRRKS MKNGQSESDDGSEQTH ESEKRPFVEEAERLRVQHKKDHPDYKYQPRRRKS VKNGQAEAEEATEQTH ESEKRPFVEEAERLRVQHKKDHPDYKYQQRRRKSVKNGQAEAEEATEQTH

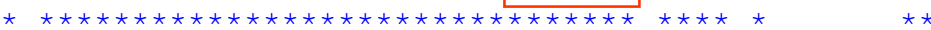

Figure 7 Alignment of salmonid and mammalian SOX9 high mobility group (HMG) domains. The mammalian and salmonid bipartite nuclear localization signal (NLS-1) and basic cluster NLS (NLS-2) are found in positions at the N- and C-termini of the HMG domain, respectively. The nuclear export signal (NES) is centrally located between the two NLSs. The C-terminal protein interface and transactivation domain residues are not shown.

sequence spanning from the 5'-UTR ending just short of the stop codon. We were unable to isolate the BAC bearing the viable foxl $2 a$ gene, but it has been mapped to linkage group (LG) 8 and foxl $2 b$ has been mapped to LG 5 in ASalBase [37]. The remaining BACs bearing the following genes have been localized to the following chromosomes by fluorescent in situ hybridization (FISH) techniques: dax1: chromosome 21 (LG14); dax2: chromosome 25 (LG20); mis: chromosome 10 (LG2) (see Additional files 9, 10 and 11).

\section{Transposon integration analysis}

SsaRT.4, a non-LTR long interspersed nuclear element (LINE) sequence [38], is integrated approximately 1.3 kbp upstream from the transcription start site of the foxl2a pseudogene (Figure 10). This fragment is truncated at the 5'-end, consistent with partial retrotranscription. Additionally, we found a fragment of the Tc1like transposon, DTSsa7 [38], inserted $800 \mathrm{bp}$ upstream from the SsaRT.4 sequence. Interestingly, a SsaRT.4 sequence was also found inserted into the centre of the intron of dax2 (Figure 10). The GT-AG signals for intron splicing are approximately 600 and 1000 nts upand downstream, respectively, from this integration. The dax 1 paralog does not possess any introns. Truncated copies of SsaRT.4 are also present in the promoter of $d a x 2$. Both the $d a x 1$ and $f o x l 2 b$ promoters appear devoid of any transposon integrations.

\section{Discussion \\ MIS}

Postnatal expression of MIS in the early mammalian male gonad leads to male reproductive tract development mediated through regression of the female anlagen [39]. The importance of MIS to male sexual differentiation is demonstrated by the morphological and endocrine sex reversal of fetal ovaries exposed to MIS [40]. The expression of MIS has been associated with the downregulation of cyp19a in mammals [40], zebrafish [41] and sea bass [27].

We have observed expression of mis in immature and mature ovary and testis of both trout and salmon (data 


\section{Atlantic salmon DAX-1 (198,947 bp)

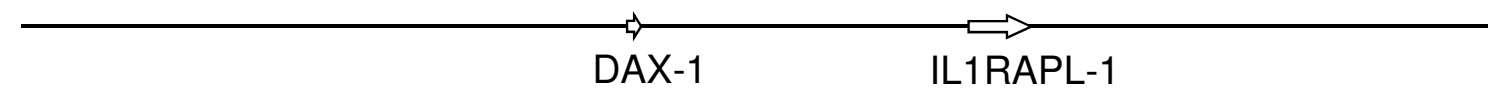

\section{Atlantic salmon DAX-2 (38,713 bp)}

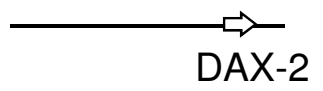

\section{Atlantic salmon FOXL2A (159,336 bp)}

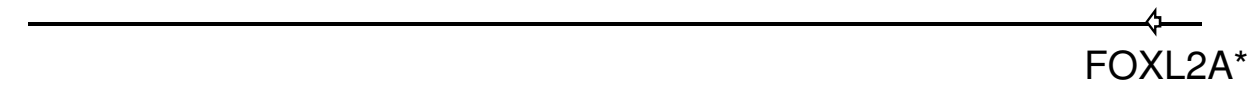

\section{Atlantic salmon FOXL2B (217,091 bp)}

\section{FOXL2B}

\section{Atlantic salmon MIS (210,036 bp)}

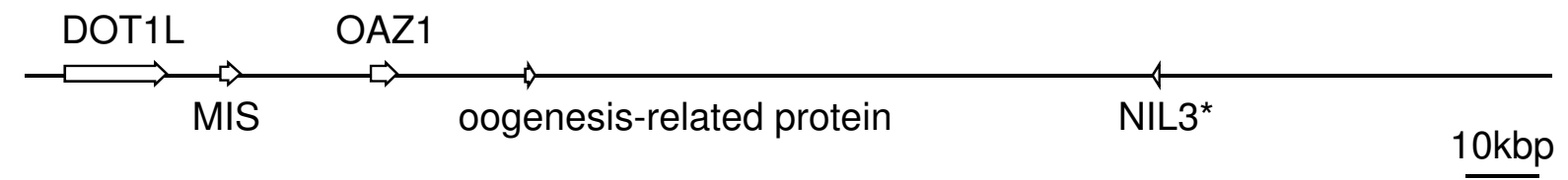

Figure 8 The genomic organization of the genes that encode DAX-1, DAX-2, FOXL2A, FOXL2B and MIS. Approximate sizes of the sequenced bacterial artificial chromosomes are indicated in parentheses. Each gene of interest and the genes that flank them are represented by boxes with transcriptional directions indicated by arrowheads. The introns for the genes are not shown. Pseudogenes are indicated by asterisks. IL1RAPL-1: X-linked interleukin-1 receptor accessory protein-like-1 precursor; DOT1L: DOT1-like histone H3 methyltransferase; NIL3: nuclear factor interleukin 3; OAZ1: ornithine decarboxylase antizyme-1.

not shown). The activity of mis was absent only in precocious or prespawn trout testis. In this study, we show expression of mis during early development and in various adult salmon tissues (Figure 2 and 3; see Additional file 2). The expression of mis by D18 indicates the potential for a role early in salmonid development. Since MIS is a glycoprotein member of the TGF $\beta$ family, it may serve in establishing and shaping different cellular phenotypes well before patterning of the reproductive tissues.

Since we observe expression of mis and the absence of cyp 19a in most adult tissues (see Additional file 2), it could be suggested that MIS downregulates cyp19a. In contrast, the expression of cyp19b1 is evident in most adult tissues. Transactivation of cyp $19 b 1$ may not be reliant on gonadotropic inputs like cyp19a (ie; cAMP stimulation $[17,23,40])$, and therefore could be refractory to inhibition by MIS. Nevertheless, unlike in mammalian models where mis expression is absent during the onset of sex determination, mis expression is detected in the embryonic gonads of both trout $[5,14]$ and tilapia [6]. Although the levels of expression in the female are much lower than in the male during the crucial sex determination window $[5,6,14]$, it may still play a role in female development. For example, disruptions to MIS signaling have been shown to impact germ cell proliferation and cell-cycle timing in both sexes of medaka [42].

Furthermore, in mammalian models, mis is the downstream regulatory target of SOX-9 activity in the differentiating testis. However, expression of $\operatorname{sox} 9 a$ and $s o x 9 b$ occurs in both the trout male and female gonad during sex determination [5]. Part of the decoupling of MIS expression from SOX regulation, at least in salmonids, could be due to the lack of canonical SOX binding elements in the proximal mis promoter (see Additional file 6). Another control mechanism that may differ in fish 


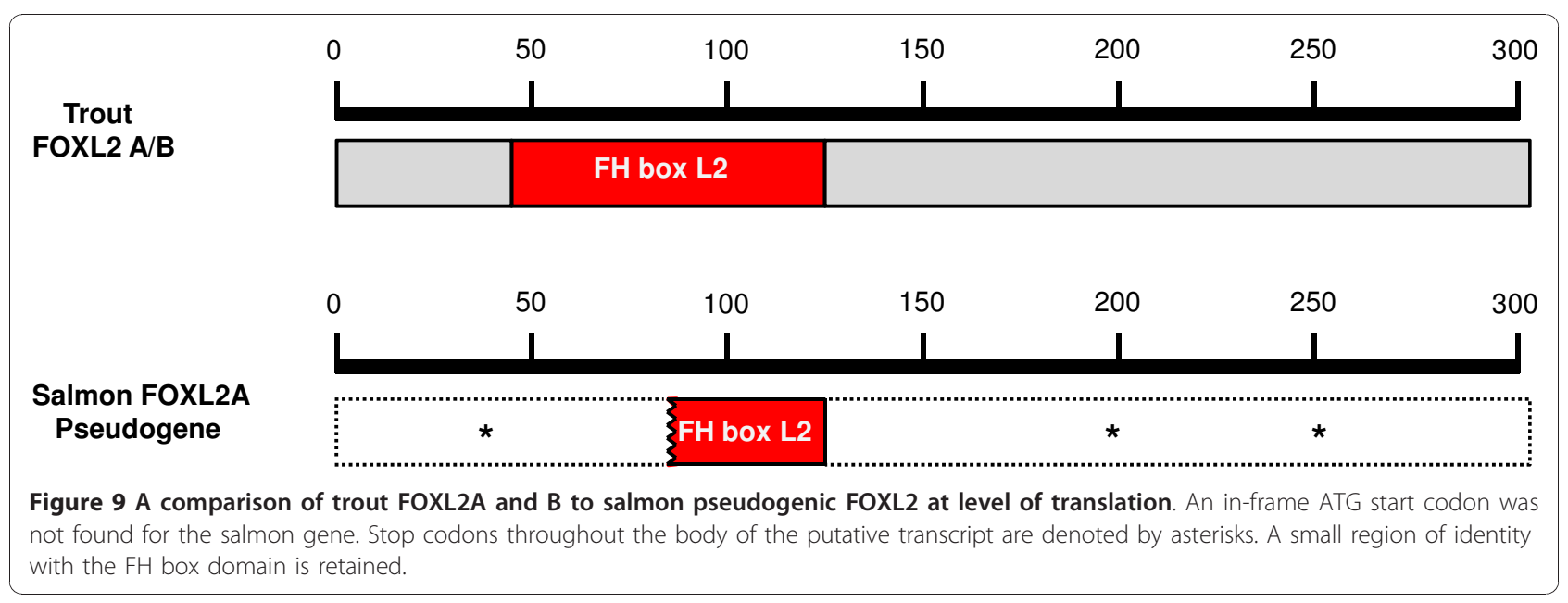

that exists in mammals is that nuclear localization of SOX-9 occurs in the male (to promote subsequent MIS transcription), but is absent in the primordial female gonad [43]. The subcellular localization signals that have been shown to direct SOX-9 nucleocytoplasmic shuttling during mammalian male sexual differentiation $[32,33]$ are highly conserved in salmonid SOX-9 proteins. Whether these signals are targets for sex-specific transport factors; and whether the sox 9 paralogs are localized to different cell-types, and are involved in

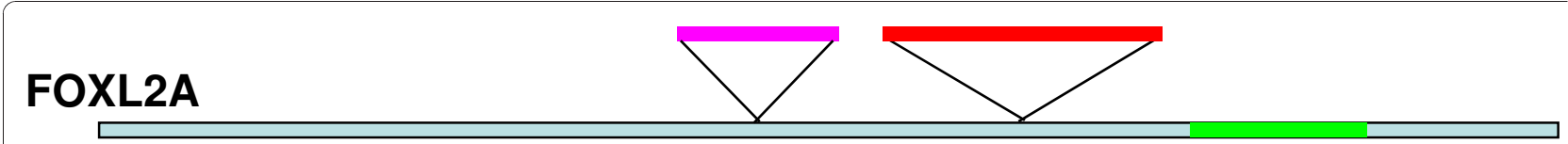

\section{FOXL2B}

\section{DAX-1}
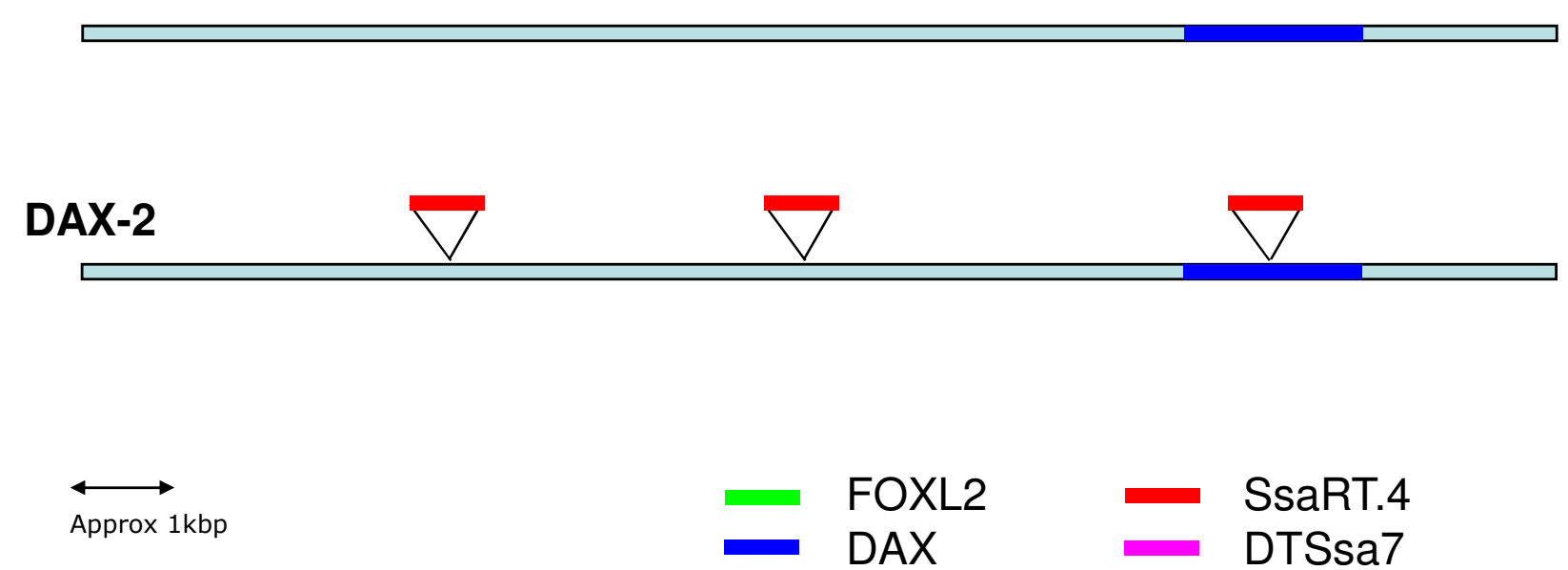

SsaRT.4

Approx $1 \mathrm{kbp}$

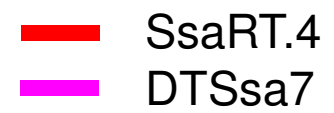

Figure 10 Transposon integration in dax and foxl2 loci. Insertion position of various transposon DNA sequences in dax and fox/2 loci are designated. 
differentiation of Sertoli precursor cells in salmonids, still remains to be determined.

In mammals, the MIS precursor protein consists of two sections - the $\mathrm{N}$-terminal prodomain and the C-terminal, mature hormone region [44]. The mammalian studies indicate that the MIS precursor protein is proteolytically cleaved at consensus RXXR sites [44]. It is not known if fish MIS proprotein is similarly proteolytically activated, but the organization and conservation of these motifs across many species does suggest similar mechanisms of hormone bioactivation [27]. Although the mammalian studies indicate that the $\mathrm{N}$-terminal prodomain section of MIS serves only to stabilize and to target the processed hormone [44], our work suggests that some mis transcripts generate only truncated prodomain representatives. The function of these transcripts, in various tissues and during early development, remains to be determined. It is possible that the expression of transcripts that encode the MIS prodomain alone may add another level of control for tissue-specific regulation of MIS activity, or that they influence the bioactivities of other members of the TGF family, such as BMPs, activin or inhibin. Heterodimerization between various members of this large family of growth factors has been shown to direct different cell-patterning decisions [45 and refs therein, 46].

\section{DAX}

DAX-1 has been described to be either a possible ovarian- or testicular-determining factor $[12,14,44,47]$. We previously found $\operatorname{dax} 1$ to be consistently expressed across all reproductive development stages examined in trout ovary and testis [23]. Although both the salmon dax 1 and dax2 described here were expressed in all adult tissues (see Additional file 2), the appearance of $\operatorname{dax} 1$ was at least two weeks before $\operatorname{dax} 2$ in salmon embryos (Figure 2).

Although the interactions that promote the undifferentiated state in embryonic stem (ES) cells are wellestablished, the events that antagonize them to initiate cellular differentiation are poorly understood. The expression of dax 1 has been associated with early mammalian ES cells in maintaining the undifferentiated state and to safeguard pluripotency $[20,48]$. OCT $3 / 4$ and SOX-2 are also considered "core" transcription factors in the maintenance of pluripotency [49]. It has been shown that these factors interact cooperatively to regulate dax1 expression in ES cells [20]. We found putative response elements for OCT3/4 and SOX factors in the dax 1 and dax 2 promoters (see Additional files 4 and 5), that implicate their role in the regulation of the salmonid genes as well.

It also has been proposed that SF-1 expression is not coupled to dax1 regulation in ES cells [20]. In this regard, it is also important to note the location of the SOX consensus binding elements in close proximity to the SF-1 motifs in both salmonid dax promoters (see Additional files 4 and 5). SOX binding of its response element may interfere with SF-1 binding during early development stages. We also show the expression of $s f 1$ no earlier than D14, a period that succeeds a potentially important differentiation transition point (see below) (Figure 2).

Regulation of alternative splicing by DAX-1 and SOX factors may control stem cell differentiation, and initiation and development of the gonad [47]. It has been demonstrated that $d a x 1$ inhibits pre-mRNA splicing of target genes and that these activities can be restored by the addition of HMG-domain containing factors [47]. Moreover, it has been proposed that the control of splicing is exerted through competiton between DAX-1 and SOX proteins for splicing factor complexes [47]. Antagonism between DAX-1 (and OCT3/4 [20]) and SOX-2 (and other HMG-domain proteins?) [47] may be the mechanism whereby "stemness" versus differentiationassociated genes are regulated in ES cells. The decline (D10), absence (D12) and reappearance (D14) of dax1 we detected (Figure 2) may reflect a transition that results in differentiation of embryonic cell layers in specific developing organs; similar to the different cell lineages that have been shown to arise following dax 1 downregulation in mouse [21,24].

\section{FOXL2}

Both foxl2 transcripts were found to be expressed very early in development (Figure 2). In the male, we found foxl $2 a$ expression to be quite restricted in comparison to the foxl $2 b$ diverged paralog, which was present in most adult extragonadal tissues examined (see Additional file 2 ). In contrast, expression of foxl $2 b$ is quite restricted in the adult female tissues, essentially confined to the skin, gill and ovary. The expression of foxl $2 b$ in the testis was also very strong, correlating well with previous findings that showed foxl $2 b$ was present, with foxl $2 a$ absent, in later stages of testis development in trout [23]. Taken together, this may indicate that foxl $2 b$ is an important regulator of male-specific genes (eg; cyp19b1), at least later in development.

The expression of foxl $2 a$ is associated with upregulation of ovarian-specific cyp $19 a$ and with differentiation of the ovary in many species $[6,14,16,17,25,26]$. Upregulation of foxl2 genes have been correlated with cyp $19 a$ expression during ovarian differentiation in trout [14], Japanese flounder [17] and Nile tilapia [6,16]. Depending on the study, transactivation of cyp $19 a$ occurs directly through the FOXL2 binding elements or in concert with SF-1. SF-1-mediated regulation of aromatase activity is modulated by DAX-1, which binds SF-1 directly $[11,15]$. 
We previously implicated FOXL2 with the generation of cyp 19b1 transcripts bearing 5'-ends of different lengths, potentially in complexes with SF-1 and DAX-1 [23]. At least two SF-1 binding sites and a number of potential FOXL2 response elements reside in the trout cyp19b1 intron 1. Because of well-characterized DAX-1 spliceosome activity (see above), and the association of both DAX-1 and SF-1 with FOXL2 at aromatase promoters in fish and mammals [6,11,15-17,25,26], we hypothesize that complexes of these gene products could also control splicing activity of cyp $19 \mathrm{~b} 1$.

This mechanism of regulatory control in the synthesis of these transcripts is further reinforced by our present characterization of the Atlantic salmon cyp19b1 intron 1 (Figure 6) which maintains many of the features described for the trout cyp19b1 intron 1 [23]. In accord with this model, we demonstrate the generation of differentially spliced, partial intron 1-containing cyp $19 b 1$ transcripts in salmon. We argue that if DAX-1, FOXL2 and SF-1 are known to interact at aromatase promoters, then nucleation at the cyp $19 b 1$ intron 1 is also plausible. Strong evidence exists that indicates that various transcription factors and nuclear hormone receptors can bind to RNA and regulate RNA splicing, migration and localization [50,51]. For example, both DAX-1 and SF-1 have been shown to bind steroid receptor activator [52], a RNA that acts as a bridge and platform to nucleate and stabilize transcription complexes. It has been proposed that nuclear receptors, such as SF-1, which can bind DNA as monomers, may recognize the YCAAGGYCR motif in RNA [52 and refs therein]. Among the various factors that bind RNA, recognition for YCAAGGYCR, as well as for other binding elements, may be through different mechanisms of interaction with the nucleic acid (e.g. zinc fingers, anti-parallel $\alpha$-helices) $[31,50,52]$.

\section{Aromatase}

In this study, we confirmed the expression of alternatively-spliced cyp19b1 transcripts in only the larvae (D38) and gonad of salmon. However, expression of cyp $19 b 1$ transcripts of different sizes and abundances are evident in a broad range of adult tissues (see Additional file 2), such as muscle (521 bp), skin (452 bp) and spleen (367 bp) of the male. Whether differences in processing results in partitioning of specific cyp $19 b 1$ transcripts to distinct tissues remains to be explored.

We also show during early salmon development that at least a three-week delay in the transcription of cyp 19a occurs in comparison to cyp19b1 (Figure 2 and 3). Part of these regulatory differences could be dictated by estrogenic or gonadotropic controls [23 and refs therein]. For example, unlike cyp $19 b$ promoters, cyp $19 a$ promoters lack consensus EREs for the fish species characterized to date $[17,18,25,53-55]$. Another important difference between these genes is that SOX binding elements, often many of them, are in close proximity to SF-1 binding motifs in teleost cyp 19a promoters $[18,25,53,54]$. Competition between SOX factors and FOXL2 for access to their binding sites on cyp19a promoters could be key to ovarian-specific aromatase synthesis. This is compatible with recent work that shows that the mammalian ovarian phenotype is mediated by cooperative FOXL2 and ER repression of sox9 transcription [22]; interactions that are opposed by the binding of SRY/SF-1 and SOX-9 in the male pathway [19]. Further work is needed to define the precise roles that FOXL2A and FOXL2B play in activation of the two salmonid cyp19 genes early in development, as well as their function in the transcription of other promoters.

\section{Genome rearrangements}

There is a growing body of evidence that demonstrates that past transposon activity has led to salmonid genome remodeling $[38,56]$. We show the integration of SsaRT.4 very close to the transcription start site of the pseudogenic foxl $2 a$ (Figure 10). Although speculative, integration of SsaRT.4 into the foxl $2 a$ regulatory region may have led to the reorganization of the 5 '-end and subsequent accumulation of stop codons into the coding region of this gene. Integration of SsaRT.4 into the dax2 intron also provides an example of how transposon activity can rearrange genes; potentially leading to the creation of introns and indicating how genes can acquire new functions over time.

\section{Conclusion}

We have found expression of many factors classically associated with sex differentiation in embryonic stages well before sex fate determination. Their expression early in development points to the potential for function during embryogenesis. Expression of these regulators in diverse adult tissues also indicates their potential role in transcription programs independent of steroidogenesis and gonadogenesis. Further investigation is required to determine if these genes are translated in the embryonic and adult stages of development and to localize their expression to specific cell-types. Whether these genes are associated with stem cells, or with other differentiation factors in networks that influence cell-patterning throughout development, remain to be unequivocally determined.

\section{Methods}

\section{Animals and Sampling}

Treatment of the fish used in this study was in compliance with the regulations of the University of Victoria Animal Care Committee. Eggs from Atlantic salmon 
(McConnell (Mowi)) were obtained in November, 2009 from Marine Harvest United Hatchery (Fanny Bay, B.C., Canada). The eggs were fertilized by gently mixing the eggs and milt by hand and then washed with partial exchanges of water. Approximately 2000 fertilized eggs were then transferred and placed in Heath trays (Marisource) at the University of Victoria. The embryos and larvae were raised in fresh water at a temperature of $12^{\circ} \mathrm{C}$ and a flow rate of 200 liters $/ \mathrm{h}$. Fry were transferred from the Heath trays to 30-liter holding tanks following yolk sac absorption.

The day of fertilization was Day (D) 0, and hatching and yolk sac absorption occurred between D38 to D40 and D68 to D70, respectively. Whole embryos $(n=20)$ were collected every other day for three weeks. Larvae were collected every third day and then alevin and fry every sixth day for the remainder of the study. Samples were directly placed into dry ice and stored at $-80^{\circ} \mathrm{C}$ until RNA extraction.

The number of mortalities were counted on each collection day. We also took several pictures using a Nikon D300 s with a $105 \mathrm{~mm} 2.8$ G_ED lens to record the progress of the development of the fish.

Twelve different Atlantic salmon (Mowi stock) tissues from three individual adult male and female fish were provided by Fisheries and Oceans Canada (West Vancouver Laboratories, West Vancouver, British Columbia). The six fish were euthanized, followed by rapid dissection of tissues (kidney, muscle, skin, gut, gill, spleen, brain, heart, gonad, liver, eye and pyloric caeca). The tissues were flash frozen in liquid nitrogen or dry ice and stored at $-80^{\circ} \mathrm{C}$ until RNA extraction.

\section{Reverse transcription and cDNA amplification}

Total RNAs were extracted in TRIzol reagent (Invitrogen) by mixer-mill homogenization (Retsch) and spincolumn purified using RNeasy Mini kits (Qiagen). The RNA from three whole embryos or two larvae or alevins was pooled for D2 to D20 and for D21 to D77 collections, respectively. RNA was extracted from portions of each adult tissue described above for each different fish. Each RNA sample was then quantified and qualitychecked by spectrophotometer (NanoDrop Technologies) and agarose gel, respectively.

The cDNAs were synthesized in $25-\mu \mathrm{L}$ reactions from $200 \mathrm{ng}$ to $1.0 \mu \mathrm{g}$ total RNA using oligo $(\mathrm{dT})_{15}$ (Promega) and Supercript II RNase $\mathrm{H}^{-}$reverse transcriptase according to the manufacturer's instructions (Invitrogen). The reactions were incubated at $37^{\circ} \mathrm{C}$ for $90 \mathrm{~min}$ and the transcriptase heat-inactivated at $70^{\circ} \mathrm{C}$ for $30 \mathrm{~min}$. Approximately 100 to $200 \mathrm{ng}$ of cDNA was used in each $25-\mu \mathrm{L}$ PCR reaction containing $1.25 \mathrm{U}$ Taq polymerase, $1 \times$ Taq buffer, $1.25 \mathrm{mM} \mathrm{MgCl}_{2}, 10 \mathrm{mM}$ dNTPs (Invitrogen) and 15 pmol of each gene-specific
5'- and 3'-primer. Each PCR was carried out under the following cycling parameters: $94^{\circ} \mathrm{C}$ for $2 \mathrm{~min}$, then 35 cycles of $94^{\circ} \mathrm{C}$ for $30 \mathrm{sec}, 55^{\circ} \mathrm{C}$ for $30 \mathrm{sec}$ (or $58^{\circ} \mathrm{C}$ for sox $9 \mathrm{~b}$ ), and $72^{\circ} \mathrm{C}$ for 1 min using a Perkin Elmer GeneAmp 9600. The PCR products were separated by electrophoresis on 1.0 to $1.5 \%$ agarose gels and photographs were stored using an UVP GelDoc-It documentation system (Ultraviolet Products).

Genomic DNA to enable isolation of the cyp19b1 intron 1 was extracted from Atlantic salmon spleen using a DNeasy Blood and Tissue kit following instructions of the manufacturer (Qiagen).

\section{PCR analysis of sex differentiation factor expression in adult tissue}

PCRs were performed with an initial denaturation step of $2 \mathrm{~min}$ at $95^{\circ} \mathrm{C}$ and then 35 cycles as follows: $30 \mathrm{sec}$ of denaturation at $95^{\circ} \mathrm{C}, 30 \mathrm{sec}$ of annealing at $55^{\circ} \mathrm{C}$ and 1 min of extension at $72^{\circ} \mathrm{C}$ using a Peltier Thermal Cycler PTC-225 (MJ Research). Amplicons for each gene of interest (GOI) were visualized on $1.0 \%$ agarose gels stained with ethidium bromide and images were stored using an UVP GelDoc-It documentation system (Ultraviolet Products). The intensity of the amplification products were semiquantitatively measured using ImageJ software [57] and divided by the intensity of the respective ubiquitin signals. The data generated was graphed in Microsoft Excel 2007 and expressed as the mean +/-SE of three individuals studied.

\section{Gene identification and primer design}

The primers used to amplify trout ovarian aromatase (cyp19a), brain aromatase (cyp19b1), dosage-sensitive sex reversal, adrenal hypoplasia congenital, critical region on the X-chromosome, gene-1 and -2 (dax 1 and 2), forkhead box L2 ortholog (foxl2a), forkhead box L2 diverged paralog $(f o x l 2 b)$, Mullerian inhibiting substance ( $m i s)$, steroidogenic factor-1 ( $s f 1)$, sex-determining region of the Y chromosome (SRY)-related high mobility group (HMG) box (SRY box) Sox9a (sox9a), Sox9b $($ sox $9 b)$, and ubiquitin (ubiq) were designed specifically against the sequences provided for each gene obtained from http://www.ncbi.nlm.nih.gov. GenBank accession numbers, primer sets and product sizes for each GOI are shown in Additional file 12. The primer sets for each target gene were designed using Primer3 software [58] and purchased from Integrated DNA Technologies. The specificity of each primer set and the identity of each amplicon were confirmed by subsequent cloning into pCR2.1-TOPO vector (Invitrogen) and sequencing.

\section{BAC screening and sequencing}

Atlantic salmon (AS) CHORI-214 [59] bacterial artificial chromosome (BAC) libraries were obtained from 
BACPAC Resources, Children's Hospital Oakland Research Institute (CHORI) [60]. AS BAC library filters were hybridized with 75-mer oligonucleotide probes for each GOI (Integrated DNA Technologies) that were 5'end-labeled with ${ }^{32} \mathrm{P}$-ATP using T4 polynucleotide kinase (Invitrogen). Filter hybridizations were conducted as described by CHORI [60].

Confirmation of each GOI-containing BAC was performed by comparisons of HindIII restriction digests of the isolated clones to in silico digests for each BAC. $\mathrm{BAC}$ clones were chosen based on the physical BAC fingerprint map for Atlantic salmon that is publicly available on the internet Contig Explorer (iCE) version 3.5 [61]. The BAC end sequence information, that is available in ASalBase [37], was also used for selection of the BAC clones.

\section{BAC preparation and library construction}

BAC DNA was isolated by an alkaline lysis procedure using Large Construct Isolation Kit (Qiagen) following the manufacturer's protocol. The isolated BAC DNA was nebulized and the DNA ends were made blunt by filling with T4 polymerase. The blunt-ended, repaired DNA was size fractioned by electrophoresis and the gel region corresponding to 1.5 to $3.0 \mathrm{~kb}$ was excised and gel purified (Qiagen). The fragments were blunt-end ligated into Sma1-cut M13mp19 vector and transformed into electrocompetent DH5 $\alpha$ E. coli cells using a BioRad Gene Pulser system. Library quality was evaluated and high redundancy plating was followed by large-scale colony picking (Genetix). Extracted recombinant plasmid templates were sequenced on an ABI 3730 DNA sequencer.

\section{BAC alignment and annotation}

Bases were called using PHRED [62,63]. High quality sequence reads were assembled using PHRAP [64] and then viewed and edited using Consed [65]. Some gaps in BAC assembly were filled by designing primers to the contiguous sequence ends, followed by amplification of the BAC region by PCR and subsequent cloning and sequencing of the fragments.

Each BAC has been deposited in GenBank as follows: BAC 33H18 containing dax1

[GenBank:HM159469]; BAC 105M10 containing dax2 [GenBank:HM159470]; BAC 217E24 containing foxl2a ortholog (pseudogene) [GenBank:HM159471]; BAC 261D01 containing foxl2b diverged paralog [GenBank: HM159472], and BAC 19C14 containing mis [GenBank: HM159473].

BAC clone sequence data were annotated using BLAST homolog searches and EMBOSS programs package [66]. Alignment of cDNA sequences against genomic sequences was done by Sequin [67], which was obtained from NCBI. Identification of transposon insertions was performed using Dotter plots [68], comparing each GOI-containing BAC with salmon transposon sequences [38].

\section{Fluorescent in situ hybridizations}

BAC DNA was labeled with Spectrum Orange using a nick translation kit (Abbott Molecular). Human placental DNA $(2 \mu \mathrm{g})$ and Cot-1 DNA $(1 \mu \mathrm{g}$, prepared from Atlantic salmon) or Cot-1 DNA (1 $\mu$ g, prepared from rainbow trout) were added to the probe mixture for blocking. Hybridizations were carried out at $37^{\circ} \mathrm{C}$ overnight and post-hybridization washes were as recommended by the manufacturer (Abbott Molecular) with minor modifications [69]. Antibodies to Spectrum Orange (Molecular Probes) were used to amplify the signal. Slides were counter-stained with 4,6-diamidino-2phenylindole (DAPI) at a concentration of $125 \mathrm{ng}$ DAPI in $1.0 \mathrm{~mL}$ antifade solution. Images were captured with a Jai camera and analyzed with Cytovision Genus (Applied Imaging, Inc.) software. Chromosomes were arranged according to size within the metacentric/submetacentric and acrocentric groups [70].

The chromosome preparations were obtained from blood of the Norwegian strain of Atlantic salmon ( $2 \mathrm{~N}=$ 58) by methods described previously for salmonid fishes [70]. Briefly, the buffy coat was isolated from whole blood and placed in MEM media with pen-strep, L-glutamine, $10 \%$ fetal calf serum and $200 \mu \mathrm{g} / \mathrm{ml} \mathrm{LPS}$ and cultured for 6 days at $20^{\circ} \mathrm{C}$. Cells were collected by centrifugation and re-suspended in $0.075 \mathrm{M} \mathrm{KCl}$ for 30 min, then fixed in 3:1 methanol acetic acid. Cell suspensions were dropped onto clean slides and allowed to dry on a slide warmer with humidity at $40^{\circ} \mathrm{C}$.

\section{Promoter analysis}

To identify the location of potential transcription factor binding elements in the promoters of our GOI, we preliminarily used MatInspector (Genomatix Software $\mathrm{GmbH}$ ). Our designation of OCT3/4 consensus binding motifs 5'-ACACGCAT-3' or 5'-ATTTGCAT-3' are based on work done in ES cells [20,71]. The HMG domain that binds to DNA is highly conserved among all SOX factors (5'-(A/T)(A/T)CAA(A/T)G-3') [72]. The SOX footprints that we also include in our analysis are based on work done on mammalian mis and cyp 19 promoters [34]. We use the term "immediate early response" element (IER) to identify response elements (5'-GCG(G/T)GGGCG-3') that potentially could bind early response products of genes such as EGR-1 and WT-1 [73]. Sequences presumed or demonstrated to bind CRE, ERE, FOXL2, PPARE, RXR/RAR and SF-1 in other fish species are also presented for each promoter examined [16-18,25,53-55,74]. 


\section{Additional material}

Additional file 1: Graphical presentation of number of mortalities found throughout early development. Day represents post-fertilization age.

Additional file 2: cDNA expression profiles for ten genes of interest in twelve different adult tissues. CDNA expression profiles for ten genes of interest (GOI) in twelve different tissues: 1: kidney, 2: muscle, 3: skin, 4: gut, 5: gill, 6: spleen, 7: brain, 8: heart, 9: testis, 10: liver, 11: eye and 12: pyloric caecum. Semi-quantitative levels of expression were calculated for each $\mathrm{GO}$ as signal intensity relative to ubiquitin levels for three individual fish. Mean values (bars) of three individuals plus standard error are shown.

Additional file 3: Alignment of partial mis transcripts. Sequence alignment of mis CDNAs and amino acid residues based on sequence upstream from the C-terminal hormone portion of salmon MIS. A. The stop codon for mis (629 bp) is highlighted in red. The open reading frame of mis (396 bp) cDNA is in-frame for encoding the bioactive hormone portion of MIS and does not contain a stop codon. Two potential protease recognition motifs (RGQR AND RATR) for translated MIS (396 bp) are boxed. B. The stop codons for mis (629 bp) and mis (436 bp) are highlighted in red. Putative cleavage RLRR recognition sites are boxed.

Additional file 4: Proximal promoter sequences of the Atlantic salmon dax 1 gene. The potential binding elements of various transcription factors, TATA boxes, exon 1 and initiator methionine codon are labeled.

Additional file 5: Proximal promoter sequences of the Atlantic salmon dax2 gene. The potential binding elements of various transcription factors, TATA boxes, exon 1 and initiator methionine codon are labeled.

Additional file 6: Proximal promoter sequences of the Atlantic salmon mis gene. The potential binding elements of various transcription factors, TATA boxes, exon 1 and initiator methionine codon are labeled.

Additional file 7: Proximal promoter sequences of the Atlantic salmon fox $/ 2 b$ gene. The potential binding elements of various transcription factors, TATA boxes, exon 1 and initiator methionine codon are labeled.

Additional file 8: Proximal promoter sequences of the Atlantic salmon pseudogenic foxl2a gene. Potential TATA boxes and the $5^{\prime}$-end portion of a region of sequence similarity shared with rainbow trout fox $/ 2$ genes are labeled.

Additional file 9: Fluorescent in situ hybridization of dax1containing BAC.

Additional file 10: Fluorescent in situ hybridization of dax2containing BAC

Additional file 11: Fluorescent in situ hybridization of miscontaining BAC

Additional file 12: Primer oligonucleotide sequences used in RT-PCRs.

\section{Abbreviations}

ARE: androgen response element; BMP: bone morphogenetic protein; CRE cyclic AMP response element; EGR-1: early growth response-1; ERE estrogen response element; OCT3/4: octamer binding factor 3/4; PPARE: peroxisome proliferator-activated receptor element; $\mathrm{RXR/RAR}$ : retinoid $\mathrm{X}$ receptor/retinoic acid receptor; SMAD: mothers against decapentaplegic; SP1: stimulatory protein-1; TGF $\beta$ : transforming growth factor $\beta$; WNT: winglessrelated MMTV integration site.

\section{Acknowledgements}

This research was supported by Genome Canada, Genome BC and the Province of $\mathrm{BC}$, and additionally by the Natural Sciences and Engineering Research Council of Canada (BFK, WSD). We are grateful to Marine Harvest for the generous donation of the Atlantic salmon eggs and to Robert Devlin (F.O.C., WestVan Lab., West Vancouver, B.C.) for providing adult fish. We are particularly indebted to Carlo Biagi, Wendy Vandersteen (RHD), Yvonne Lai and Krzysztof Lubieniecki (WSD) for their adept extractions and handling of tissues. We appreciate very much the help of Brendon Campbell, Amy Hoare and Brian Ringwood for egg transport and care of the young fish (Animal Care Services, University of Victoria). We thank Roderick Haesevoets, Sherri Brady and Stephanie Puckett for clone sequencing (CBR DNA Sequencing Facility, University of Victoria).

\section{Author details}

'Department of Biology, Centre for Biomedical Research, University of Victoria, Victoria, British Columbia, V8W 3N5, Canada. ${ }^{2}$ Tokyo University of Marine Science and Technology, Tateyama, Chiba, 294-0308, Japan. ${ }^{3}$ Biological Sciences, Washington State University, Vancouver, Washington, 98686-9600, USA. ${ }^{4}$ Department of Molecular Biology and Biochemistry, Simon Fraser University, Burnaby, British Columbia, V5A 1S6, Canada.

\section{Authors' contributions}

KRVS designed and coordinated the study, performed GOI-specific PCRs of early development stage CDNAs, promoter analysis and drafted the manuscript. MY performed GOI-specific PCRs of adult tissue CDNAs and semi-quantitative analysis. RY performed BAC sequence data analysis and annotations. JdB performed transposable element analysis. LR performed hybridizations to isolate and identify GOI-containing BACs. SS, AR and EBR performed BAC clone preparation and sequencing. RBP performed FISH on BAC DNA. WSD and BFK obtained funding and contributed to experimental design and analysis. All authors read and approved the final manuscript.

Received: 22 July 2010 Accepted: 13 January 2011

Published: 13 January 2011

\section{References}

1. Yao HH, Matzuk MM, Jorgez CJ, Menke DB, Page DC, Swain A, Capel B: Follistatin operates downstream of Wnt4 in mammalian ovary organogenesis. Dev Dyn 2004, 230(2):210-215.

2. Kim Y, Capel B: Balancing the bipotential gonad between alternative organ fates: a new perspective on an old problem. Dev Dyn 2006 235(9):2292-2300.

3. Park SY, Jameson JL: Minireview: transcriptional regulation of gonadal development and differentiation. Endocrinology 2005, 146(3):1035-1042.

4. Yao HH: The pathway to femaleness: current knowledge on embryonic development of the ovary. Mol Cell Endocrinol 2005, 230(1-2):87-93.

5. Vizziano D, Randuineau G, Baron D, Cauty C, Guiguen Y: Characterization of early molecular sex differentiation in rainbow trout,Oncorhynchus mykiss. Dev Dyn 2007, 236(8):2198-2206.

6. ljiri S, Kaneko H, Kobayashi T, Wang DS, Sakai F, Paul-Prasanth B, Nakamura M, Nagahama Y: Sexual dimorphic expression of genes in gonads during early differentiation of a teleost fish, the Nile tilapia Oreochromis niloticus. Biol Reprod 2008, 78(2):333-341.

7. von Schalburg KR, Rise ML, Brown GD, Davidson WS, Koop BF: A comprehensive survey of the genes involved in maturation and development of the rainbow trout ovary. Biol Reprod 2005, 72(3):687-99.

8. von Schalburg KR, McCarthy SP, Rise ML, Hutson JC, Davidson WS, Koop BF: Expression of morphogenic genes in mature ovarian and testicular tissues: potential stem-cell niche markers and patterning factors. Mol Reprod Dev 2006, 73(2):142-152.

9. von Schalburg KR, Cooper GA, Yazawa R, Davidson WS, Koop BF: Microarray analysis reveals differences in expression of cell surface and extracellular matrix components during development of the trout ovary and testis. Comp Biochem Physiol 2008, 3:78-90.

10. Ikeda Y, Swain A, Weber TJ, Hentges KE, Zanaria E, Lalli E, Tamai KT, Sassone-Corsi P, Lovell-Badge R, Camerino G, Parker KL: Steroidogenic factor 1 and Dax-1 colocalize in multiple cell lineages: potential links in endocrine development. Mol Endocrinol 1996, 10(10):1261-1272.

11. Wang ZJ, Jeffs B, Ito M, Achermann JC, Yu RN, Hales DB, Jameson JL: Aromatase (Cyp19) expression is up-regulated by targeted disruption of Dax1. Proc Natl Acad Sci USA 2001, 98(14):7988-7993.

12. Tremblay JJ, Viger RS: Nuclear receptor Dax-1 represses the transcriptional cooperation between GATA-4 and SF-1 in Sertoli cells. Biol Reprod 2001, 64(4):1191-1199. 
13. Nachtigal MW, Hirokawa Y, Enyeart-VanHouten DL, Flanagan JN, Hammer GD, Ingraham HA: Wilms' tumor 1 and Dax-1 modulate the orphan nuclear receptor SF-1 in sex-specific gene expression. Cell 1998, 93(3):445-454.

14. Baron D, Houlgatte R, Fostier A, Guiguen Y: Large-scale temporal gene expression profiling during gonadal differentiation and early gametogenesis in rainbow trout. Biol Reprod 2005, 73(5):959-966.

15. Nakamoto M, Wang DS, Suzuki A, Matsuda M, Nagahama Y, Shibata N: Dax1 suppresses P450arom expression in medaka ovarian follicles. $\mathrm{Mol}$ Reprod Dev 2007, 74(10):1239-1246.

16. Wang DS, Kobayashi T, Zhou LY, Paul-Prasanth B, Ijiri S, Sakai F, Okubo K, Morohashi K, Nagahama Y: Foxl2 up-regulates aromatase gene transcription in a female-specific manner by binding to the promoter as well as interacting with ad4 binding protein/steroidogenic factor $1 . \mathrm{Mol}$ Endocrinol 2007, 21(3):712-725.

17. Yamaguchi T, Yamaguchi S, Hirai T, Kitano T: Follicle-stimulating hormone signaling and Foxl2 are involved in transcriptional regulation of aromatase gene during gonadal sex differentiation in Japanese flounder, Paralichthys olivaceus. Biochem Biophys Res Commun 2007, 359(4):935-940.

18. Chang X, Kobayashi T, Senthilkumaran B, Kobayashi-Kajura H, Sudhakumari CC, Nagahama Y: Two types of aromatase with different encoding genes, tissue distribution and developmental expression in Nile tilapia (Oreochromis niloticus). Gen Comp Endocrinol 2005, 141(2):101-115.

19. Sekido R, Lovell-Badge R: Sex determination involves synergistic action of SRY and SF1 on a specific Sox9 enhancer. Nature 2008, 453(7197):930-934.

20. Sun C, Nakatake Y, Ura H, Akagi T, Niwa H, Koide H, Yokota T: Stem cellspecific expression of Dax 1 is conferred by STAT3 and Oct3/4 in embryonic stem cells. Biochem Biophys Res Commun 2008, 372(1):91-96.

21. Khalfallah $\mathrm{O}$, Rouleau M, Barbry P, Bardoni B, Lalli E: Dax-1 knockdown in mouse embryonic stem cells induces loss of pluripotency and multilineage differentiation. Stem Cells 2009, 27(7):1529-1537.

22. Uhlenhaut NH, Jakob S, Anlag K, Eisenberger T, Sekido R, Kress J, Treier AC, Klugmann C, Klasen C, Holter NI, Riethmacher D, Schütz G, Cooney AJ, Lovell-Badge $\mathrm{R}$, Treier M: Somatic sex reprogramming of adult ovaries to testes by FOXL2 ablation. Cell 2009, 139(6):1130-1142.

23. von Schalburg KR, Yasuike M, Davidson WS, Koop BF: Regulation, expression and characterization of aromatase (cyp19b1) transcripts in ovary and testis of rainbow trout (Oncorhynchus mykiss). Comp Biochem Physiol B 2010, 155(2):118-125.

24. Clipsham R, Niakan K, McCabe ER: NrOb1 and its network partners are expressed early in murine embryos prior to steroidogenic axis organogenesis. Gene Expr Patterns 2004, 4(1):3-14.

25. Galay-Burgos M, Gealy C, Navarro-Martín L, Piferrer F, Zanuy S, Sweeney GE: Cloning of the promoter from the gonadal aromatase gene of the European sea bass and identification of single nucleotide polymorphisms. Comp Biochem Physiol A 2006, 145(1):47-53.

26. Pannetier M, Fabre S, Batista F, Kocer A, Renault L, Jolivet G, MandonPépin B, Cotinot C, Veitia R, Pailhoux E: FOXL2 activates P450 aromatase gene transcription: towards a better characterization of the early steps of mammalian ovarian development. J Mol Endocrinol 2006, 36(3):399-413.

27. Halm S, Rocha A, Miura T, Prat F, Zanuy S: Anti-Müllerian hormone (AMH) $\mathrm{AMH})$ in the European sea bass: its gene structure, regulatory elements, and the expression of alternatively-spliced isoforms. Gene 2007, 388(1-2)):148-158.

28. Toffolo V, Belvedere P, Colombo L, Valle LD: Tissue-specific transcriptional initiation of the CYP19 genes in rainbow trout, with analysis of splicing patterns and promoter sequences. Gen Comp Endocrinol 2007, 153(13):311-319.

29. Shapiro MB, Senapathy P: RNA splice junctions of different classes of eukaryotes: sequence statistics and functional implications in gene expression. Nucleic Acids Res 1987, 15(17):7155-7174

30. Zheng Z-M: Regulation of alternative RNA splicing by exon definition and exon sequences in viral and mammalian gene expression. $J$ Biomed Sci 2004, 11:278-294

31. Little TH, Zhang Y, Matulis CK, Weck J, Zhang Z, Ramachandran A, Mayo KE, Radhakrishnan I: Sequence-specific deoxyribonucleic acid (DNA) recognition by steroidogenic factor 1 : a helix at the carboxy terminus of the DNA binding domain is necessary for complex stability. Mol Endocrinol 2006, 20(4):831-843.
32. Südbeck P, Scherer G: Two independent nuclear localization signals are present in the DNA-binding high-mobility group domains of SRY and SOX9. J Biol Chem 1997, 272(44):27848-27852.

33. Gasca S, Canizares J, De Santa Barbara P, Mejean C, Poulat F, Berta P, BoizetBonhoure B: A nuclear export signal within the high mobility group domain regulates the nucleocytoplasmic translocation of SOX9 during sexual determination. Proc Natl Acad Sci USA 2002, 99(17):11199-11204

34. Haqq CM, King CY, Donahoe PK, Weiss MA: SRY recognizes conserved DNA sites in sex-specific promoters. Proc Natl Acad Sci USA 1993, 90(3):1097-1101.

35. Hagen G, Müller S, Beato M, Suske G: Cloning by recognition site screening of two novel GT box binding proteins: a family of Sp1 related genes. Nucleic Acids Res 1992, 20(21):5519-5525.

36. Park GT, Morasso Ml: Bone morphogenetic protein-2 (BMP-2) transactivates Dlx3 through Smad1 and Smad4: alternative mode for Dlx3 induction in mouse keratinocytes. Nucleic Acids Res 2002, 30(2):515-522.

37. ASalBase. [http://www.asalbase.org]

38. de Boer JG, Yazawa R, Davidson WS, Koop BF: Bursts and horizontal evolution of DNA transposons in the speciation of pseudotetraploid salmonids. BMC Genomics 2007, 8:422-431.

39. Teixeira J, Maheswaran S, Donahoe PK: Müllerian inhibiting substance: an instructive developmental hormone with diagnostic and possible therapeutic applications. Endocr Rev 2001, 22(5):657-674.

40. Vigier B, Forest MG, Eychenne B, Bézard J, Garrigou O, Robel P, Josso N: Anti-Müllerian hormone produces endocrine sex reversal of fetal ovaries. Proc Natl Acad Sci USA 1989, 86(10):3684-3688.

41. Rodríguez-Marí A, Yan YL, Bremiller RA, Wilson C, Cañestro C, Postlethwait $\mathrm{JH}$ : Characterization and expression pattern of zebrafish Anti-Müllerian hormone (Amh) relative to sox9a, sox9b, and cyp19a1a, during gonad development. Gene Expr Patterns 2005, 5(5):655-667.

42. Morinaga C, Saito D, Nakamura S, Sasaki T, Asakawa S, Shimizu N, Mitani H, Furutani-Seiki M, Tanaka M, Kondoh H: The hotei mutation of medaka in the anti-Mullerian hormone receptor causes the dysregulation of germ cell and sexual development. Proc Natl Acad Sci USA 2007, 104(23):9691-9696.

43. Schmahl J, Kim Y, Colvin JS, Ornitz DM, Capel B: Fgf9 induces proliferation and nuclear localization of FGFR2 in Sertoli precursors during male sex determination. Development 2004, 131(15):3627-3636.

44. Nachtigal MW, Ingraham HA: Bioactivation of Müllerian inhibiting substance during gonadal development by a kex2/subtilisin-like endoprotease. Proc Natl Acad Sci USA 1996, 93(15):7711-7716.

45. Eimon PM, Harland RM: Effects of heterodimerization and proteolytic processing on Derrière and Nodal activity: implications for mesoderm induction in Xenopus. Development 2002, 129(13):3089-3103.

46. Nishimatsu S, Thomsen GH: Ventral mesoderm induction and patterning by bone morphogenetic protein heterodimers in Xenopus embryos. Mech Dev 1998, 74(1-2):75-88.

47. Ohe K, Tamai KT, Parvinen M, Sassone-Corsi P: DAX-1 and SOX6 molecular interplay results in an antagonistic effect in pre-mRNA splicing. Dev Dyn 2009, 238(6):1595-1604.

48. Niakan KK, Davis EC, Clipsham RC, Jiang M, Dehart DB, Sulik KK, McCabe ER: Novel role for the orphan nuclear receptor Dax1 in embryogenesis, different from steroidogenesis. Mol Genet Metab 2006, 88(3):261-271.

49. Takahashi K, Yamanaka S: Induction of pluripotent stem cells from mouse embryonic and adult fibroblast cultures by defined factors. Cell 2006, 126(4):663-676.

50. Lalli E, Ohe K, Hindelang C, Sassone-Corsi P: Orphan receptor DAX-1 is a shuttling RNA binding protein associated with polyribosomes via mRNA. Mol Cell Biol 2000, 20(13):4910-4921.

51. Lalli E, Ohe K, Latorre E, Bianchi ME, Sassone-Corsi P: Sexy splicing: regulatory interplays governing sex determination from Drosophila to mammals. J Cell Sci 2003, 116(3):441-445.

52. Xu B, Yang WH, Gerin I, Hu CD, Hammer GD, Koenig RJ: Dax-1 and steroid receptor RNA activator (SRA) function as transcriptional coactivators for steroidogenic factor 1 in steroidogenesis. Mol Cell Biol 2009, 29(7):1719-1734

53. Callard GV, Tchoudakova AV, Kishida M, Wood E: Differential tissue distribution developmental programming, estrogen regulation and promoter characteristics of cyp19 genes in teleost fish. J Steroid Biochem Mol Biol 2001, 79(1-5):305-314. 
54. Kanda H, Okubo T, Omori N, Niihara H, Matsumoto N, Yamada K, Yoshimoto S, Ito M, Yamashita S, Shiba T, Takamatsu N: Transcriptional regulation of the rainbow trout CYP19a gene by FTZ-F1 homologue. J Steroid Biochem Mol Biol 2006, 99(2-3):85-92.

55. Wong TT, ljiri S, Zohar Y: Molecular biology of ovarian aromatase in sex reversal: complementary DNA and 5'-flanking region isolation and differential expression of ovarian aromatase in the gilthead seabream (Sparus aurata). Biol Reprod 2006, 74(5):857-864.

56. von Schalburg KR, Yazawa R, de Boer J, Lubieniecki KP, Goh B, Straub CA, Beetz-Sargent MR, Robb A, Davidson WS, Devlin RH, Koop BF: Isolation, characterization and comparison of Atlantic and Chinook salmon growth hormone 1 and 2. BMC Genomics 2008, 9:522-534.

57. Image J. [http://rsbweb.nih.gov/ij/].

58. Primer3. [http://frodo.wi.mit.edu].

59. Thorsen J, Zhu B, Frengen E, Osoegawa K, de Jong PJ, Koop BF, Davidson WS, Høyheim B: A highly redundant BAC library of Atlantic salmon (Salmo salar): an important tool for salmon projects. $B M C$ Genomics 2005, 6(1):50-57.

60. CHORI - Children's Hospital Oakland Research Institute. [http://bacpac.chori. org/highdensity.htm].

61. iCE - internet Contig Explorer. [http://www.bcgsc.ca/platform/bioinfo/ software/ice].

62. Ewing $B$, Green P: Base-calling of automated sequencer traces using PHRED. II Error probabilities. Genome Res 1998, 8:186-194.

63. Ewing B, Hillier L, Wendl MC, Green P: Base-calling of automated sequencer traces using PHRED. I. Accuracy assessment. Genome Res 1998, 8:175-185.

64. PHRAP. [http://bozeman.mbt.washington.edu].

65. Gordon D, Abajan C, Green P: Consed: a graphical tool for sequence finishing. Genome Res 1998, 8:195-202.

66. EMBOSS. [http://emboss.sourceforge.net/]

67. Altschul SF, Gish W, Miller W, Myers EW, Lipman DJ: Basic local alignment search tool. J Mol Biol 1990, 215:403-410.

68. Sonnhammer EL, Durbin R: A dot-matrix program with dynamic threshold control suited for genomic DNA and protein sequence analysis. Gene 1995, 167:GC1-10.

69. Phillips RB, Nichols KM, DeKoning JJ, Morasch MR, Keatley KA, Rexroad C, Gahr SA, Danzmann RG, Drew RE, Thorgaard GH: Assignment of rainbow trout linkage groups to specific chromosomes. Genetics 2006, 174(3):1661-1670.

70. Phillips RB, Keatley KA, Morasch MR, Ventura AB, Lubieniecki KP, Koop BF, Danzmann RG, Davidson WS: Assignment of Atlantic salmon (Salmo salar) linkage groups to specific chromosomes: conservation of large syntenic blocks corresponding to whole chromosome arms in rainbow trout (Oncorhynchus mykiss). BMC Genet 2009, 10:46-56.

71. Sun C, Nakatake Y, Akagi T, Ura H, Matsuda T, Nishiyama A, Koide H, Ko MS, Niwa H, Yokota T: Dax1 binds to Oct3/4 and inhibits its transcriptional activity in embryonic stem cells. Mol Cell Biol 2009, 29(16):4574-4583.

72. Wilson M, Koopman P: Matching SOX: partner proteins and co-factors of the SOX family of transcriptional regulators. Curr Opin Genet Dev 2002, 12(4):441-446.

73. Tremblay JJ, Drouin J: Egr-1 is a downstream effector of GnRH and synergizes by direct interaction with Ptx1 and SF-1 to enhance luteinizing hormone beta gene transcription. Mol Cell Biol 1999, 19(4):2567-2576.

74. Yang BY, Chan KM, Lin CM, Chen $\Pi$ : Characterization of rainbow trout (Oncorhynchus mykiss) growth hormone 1 gene and the promoter region of growth hormone 2 gene. Arch Biochem Biophys 1997, 340(2):359-368.

doi:10.1186/1471-2164-12-31

Cite this article as: von Schalburg et al:: Regulation and expression of sexual differentiation factors in embryonic and extragonadal tissues of Atlantic salmon. BMC Genomics 2011 12:31.

\section{Submit your next manuscript to BioMed Central and take full advantage of:}

- Convenient online submission

- Thorough peer review

- No space constraints or color figure charges

- Immediate publication on acceptance

- Inclusion in PubMed, CAS, Scopus and Google Scholar

- Research which is freely available for redistribution

Submit your manuscript at www.biomedcentral.com/submit
C Biomed Central 